TITLE:

\title{
Facile strategy for obtaining luminescent polymorphs based on the chirality of a boron-fused azomethine complex
}

\section{AUTHOR(S):}

Ohtani, Shunsuke; Takeda, Yusuke; Gon, Masayuki; Tanaka, Kazuo; Chujo, Yoshiki

\section{CITATION:}

Ohtani, Shunsuke ... [et al]. Facile strategy for obtaining luminescent polymorphs based on the chirality of a boron-fused azomethine complex. Chemical Communications 2020, 56(97): 15305-15308

ISSUE DATE:

2020-12-18

URL:

http://hdl.handle.net/2433/260850

\section{RIGHT:}

This is the accepted manuscript of the article, which has been published in final form at

https://doi.org/10.1039/d0cc06383e.; The full-text file will be made open to the public on 20 November 2021 in

accordance with publisher's 'Terms and Conditions for Self-Archiving'; この論文は出版社版でありません。引用の際に は出版社版をご確認ご利用ください。; This is not the published version. Please cite only the published version. 


\section{COMMUNICATION}

\section{Facile Strategy for Obtaining Luminescent Polymorphs Based on Chirality of Boron-Fused Azomethine Complex}

Received 00th January 20xx, Accepted 00th January 20xx DOI: $10.1039 / \times 0 \times x 00000 x$

\author{
Shunsuke Ohtani, Yusuke Takeda, Masayuki Gon, Kazuo Tanaka* and Yoshiki Chujo
}

A chloro-substituted boron-fused azomethine complex (BAmCl) having a stereogenic boron center was synthesized for obtaining a luminescent chiral crystal. We succeeded in isolating the $(R)$ - and (S)-enantiomers of $\mathrm{BAmCl}$ and preparing the homochiral polymorphic crystal, while we obtained the racemic crystal with rac-BAmCl. Single crystal $\mathrm{X}$-ray diffraction analyses suggest that a variety of intermolecular interaction patterns and intrinsic flexibility of the molecular framework should play a significant role in stabilizing the homochiral crystal. We found the difference in molecular arrangements between the racemic and the homochiral crystals, and we observed distinct different emission colors. In particular, we observed heat-initiated homogeneous racemization without the need for a solvent or catalyst in the molten state of the homochiral crystal $(R)-\mathrm{BAmCl}$. Our results mean that chiral resolution of a flexible fused-skeleton having a stereogenic boron center can be a platform for creating luminescent polymorphic materials.

Organic chromophores with variable solid-state emission properties have gathered considerable attention as a platform for realizing advanced organic devices such as, luminescent sensors for monitoring slight environmental changes ${ }^{1}$ and bioprobes for assessing biological events and reactions. ${ }^{2}$ Recently, we developed various types of solid-state luminescent molecules with stimuli-responsivity based on the concept of "element-blocks", which are minimum functional units containing heteroatoms, to create functional luminescent materials. ${ }^{3}$ In the series of studies, we discovered that boronfused complexes with tridentate ligands exhibited superior solid-state emission and unique environment responsivity. ${ }^{4}$ In particular, we found that the boron-fused azomethine complex BAm showed crystallization-induced emission (CIE) propertya, where less-emissive molecules in solution are turned to be

a. Department of Polymer Chemistry, Graduate School of Engineering, Kyoto University Katsura, Nishikyo-ku, Kyoto 615-8510, Japan. E-mail:

tanaka@poly.synchem.kyoto-u.ac.jp

b. + Electronic Supplementary Information (ESI) available. See DOI: $10.1039 / x 0 x \times 00000 x$ strongly emissive in crystal. ${ }^{5}$ We revealed that the restriction of molecular motions is responsible for emission enhancement in solid. Interestingly, the two polymorphic crystals of BAm were obtained and their emissive colors were critically different.

Polymorphism alteration is currently recognized as a promising strategy to tune a crystalline-state emissive property and various types of optically-functional materials have been developed. ${ }^{6}$ However, precise controls of polymorphism are extensively challenging because it is difficult to predict whether a newly synthesized compound is polymorphic or not. To propose one solve for this problem, we focus on the stereogenic boron center of BAm. According to the above-mentioned previous research, we obtained the two polymorphs as racemic crystals consisting of $(R)$ - and $(S)$-enantiomers of BAm. In particular, conventional organic luminescent dyes usually show poor emission in solid due to concentration quenching originated form intermolecular interactions, meanwhile BAm can provide not only intense emission in crystal but also different luminescent colors between polymorphs. On the basis of these data, we assumed that another luminescent homochiral crystal would be available by the chiral resolution. However, according to the so-called Wallach's rule, homochiral crystals are empirically less stable than the corresponding racemic crystals due to the inefficient molecular packing. ${ }^{7}$ In fact, our preliminary experiment suggested that the crystallinities of the separated BAm enantiomers were extremely poor, and we failed to get the homochiral crystal. Therefore, further elaboration must be required for preserving homochiral states.

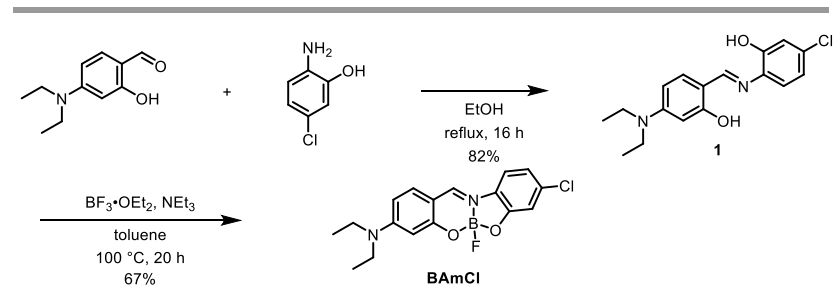

Scheme 1. Synthetic route of BAmCl. 
Although organoboron compounds have been considered to be a class of highly-efficient luminescent dyes, a large number of luminescent boron complexes are achiral or racemic mixtures. ${ }^{8}$ Especially, there are only a few examples to be resolved despite the easy introduction of chiral elements into $\pi$ conjugated skeleton. ${ }^{9}$ In this work, we synthesized a new BAm derivative with the chlorine substitution, which can provide additional intermolecular interactions to enhance the crystallinity of enantiopure samples. As a result, we succeeded in obtaining the homochiral crystal as well as the racemic crystal. From the result of a single crystal X-ray diffraction (SCXRD) analysis, it was proposed that a variety of the intermolecular interactions and the intrinsic flexibility of BAm framework contributed to the stabilization of the homochiral crystal. Moreover, these two crystals showed different emission colors dependent on the molecular arrangements. Additionally, in the homochiral crystal, the homogeneous racemization was observed through the molten state in the absence of any solvents and catalysts. To the best of our knowledge, this is the first example of homogeneous racemization in the boroncentered chiral compounds.

The synthetic route to $\mathbf{B A m C l}$ is shown in Schemes 1 and S1S2. The chlorine-substituted azomethine ligand $\mathbf{1}$ was prepared by a conventional condensation reaction ( $82 \%$ isolated yield). Subsequently, BAmCl was obtained from $\mathbf{1}$ as a racemic mixture by boron complexation in $67 \%$ isolated yield. The structure of BAmCl was examined by ${ }^{1} \mathrm{H},{ }^{11} \mathrm{~B},{ }^{13} \mathrm{C} N M R$, ionization mass measurements and elemental analyses (Fig. S1-S8), and we concluded the desired molecule was obtained with high purity. The chiral resolution of the racemic mixture of $\mathbf{B A m C l}$ was carried out through chiral high-performance liquid chromatography (HPLC) using an amylose-based stationary phase with $n$-hexane/THF ( $/ v=1 / 3$ ) as an eluent (See Table S1 for detail analysis condition). The chiral HPLC profile showed the two peaks attributable to $(R)$ - and $(S)$-enantiomoers (Fig. S9). From the peak integral ratios, it was found that $\mathbf{B A m C l}$ existed in racemic mixture with almost the same ratio (Peak 1: 51\%, Peak 2: 49\%). The two peaks were successfully resolved into two fractions, BAmCl-fr1 and $\mathbf{B A m C l - f r 2 , ~ w i t h ~ t h e ~ r e t e n t i o n ~ t i m e s ~ o f ~}$ $57.2 \mathrm{~min}$ and $62.6 \mathrm{~min}$, respectively (flow rate: $3.5 \mathrm{~mL} / \mathrm{min}$ ). From the results of the enantiomer peak integrals, BAmCl-fr1 and $\mathbf{B A m C l}-\mathbf{f r} \mathbf{2}$ were determined as $>99 \%$ enantiomeric excess (ee) and $95 \%$ ee, respectively. The ee value of BAmCl-fr2 was lifted to $97 \%$ after recrystallization. Fig. S10 shows the circular dichroism (CD) and UV-vis absorption spectra for BAmCl-fr1 and BAmCl-fr2. The mirror image in $\mathrm{CD}$ spectra from both fractions means that the two fractions should be a pair of enantiomers. In order to ensure the stability of the chirality, the time-dependent $C D$ measurement was conducted with the toluene solution of BAmCl-fr1 at $80{ }^{\circ} \mathrm{C}$ (Fig. S11). Significant racemization was hardly observed even after heating for $4 \mathrm{~h}$, suggesting that the chirality on the stereogenic boron center in the boron-fused azomethine complex system was enough stable to evaluate the properties under ambient conditions.

The SCXRD analysis elucidated that the racemic crystal obtained from rac-BAmCl belongs to the centrosymmetric space group $P 2_{1} / c$ (Table S2). Fig. 1a represents the packing

mode of rac-BAmCl and the molecules show a dimeric motif of alternating adjacent $(R)$ - and $(S)$ - $\mathbf{B A m C l}$. From the analyses of short contacts between the molecules, the existence of relatively strong halogen-based hydrogen bonds $(\mathrm{CH} \cdots \mathrm{F}$ or $\mathrm{Cl})$ was proposed. In particular, the dimeric molecular motif was stabilized by the formation of two equivalent $\mathrm{CH} \cdots \mathrm{F}$ hydrogen bonding interactions between each molecule's fluorine atom and aromatic hydrogen atom (Fig. S12). By contrast, from the molecular arrangement of BAmCl-fr1, it was found that three $(R)$-BAmCl molecules formed helical stacking columns in the unit cell and $\mathrm{CH} \cdots \mathrm{F}$ hydrogen bonding interactions were observed among them (Fig. S13). The space group belongs to the noncentrosymmetric $P 3_{2}$, indicating BAmCl-fr1 crystalizes as a chiral crystal (Table S3). The Flack parameter was refined to $0.06(2)$, confirming the $(R)$-configuration at the boron stereocenter. From these results, the remaining BAmCl-fr2 was assigned as (S)-BAmCl (hereinafter, the crystals obtained from BAmCl-fr1 and BAmCl-fr2 are called (R)-BAmCl and (S)-BAmCl, respectively). Moreover, the diethylamine groups $\mathrm{CH} \cdots \mathrm{Cl}$ hydrogen bonding were observed among the adjacent helical molecular columns, suggesting that the chlorine atom had some degree of contribution to stabilization of the chiral crystal structure (Fig. S13).

In both crystal structures, there seems to be subtle interfacial $\pi-\pi$ interactions in the crystal packing owing to steric hindrance imposed by the distorted $\pi$-conjugated system and the protruded fluorine atom as we previously reported. ${ }^{4}$ Meanwhile, $\mathrm{CH} \cdots \pi$ interactions were also observed between multiple $\mathrm{H}$ atoms and two aromatic phenyl rings in addition to the halogen-based hydrogen bonding (Fig. S12 and S13). In comparison to the molecular structures of crystals, it is clearly shown that the dihedral angle between two phenyl groups totally differs among them (rac-BAmCl: $165.5^{\circ}$; (R)-BAmCl: $\left.156.8^{\circ}\right)$. These facts indicate that the boron-fused structure of BAmCl can adopt suitable molecular conformation dependent on molecular packings. In general, the conformational flexibility is advantageous for obtaining polymorphs because variable structures are acceptable in flexible molecules more than rigid ones. ${ }^{10}$ In this regard, the flexible molecular framework of BAmCl should play a significant role in the formation of chiral

a)

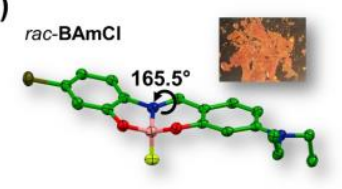

b)
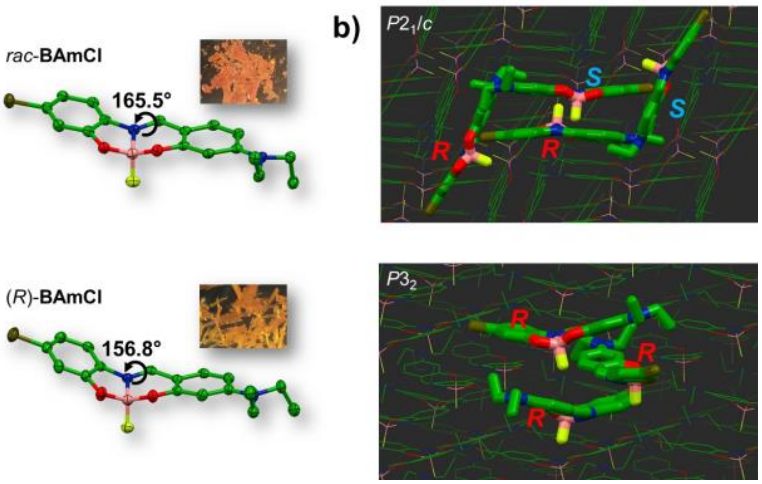

Fig. 1 a) Thermal ellipsoid (probability level 50\%) and b) packing structures of rac-BAmCl and $(R)$-BAmCl (green carbon atoms; blue nitrogen atoms; red oxygen atoms; pink boron atoms; yellow fluorine atoms; gold chlorine atoms; hydrogen atoms are omitted for clarity). 
Table 1 Optical properties of BAmCl

\begin{tabular}{|c|c|c|c|c|c|}
\hline & $\begin{array}{l}\lambda_{\max , \text { abs }} \\
(\mathrm{nm})^{d}\end{array}$ & $\begin{array}{c}\lambda_{\mathrm{em}} \\
(\mathrm{nm})^{e}\end{array}$ & $\Phi_{\mathrm{F}}^{f}$ & $\begin{array}{c}k_{\mathrm{r}} \\
\left(\times 10^{7} \mathrm{~s}^{-1}\right)^{g}\end{array}$ & $\begin{array}{c}k_{\mathrm{nr}} \\
\left(\times 10^{8} \mathrm{~s}^{-1}\right)^{g}\end{array}$ \\
\hline Sol. ${ }^{a}$ & $\begin{array}{l}445 \\
464\end{array}$ & 526 & 0.002 & 0.17 & 87 \\
\hline Amor. $^{b}$ & - & - & $<0.001$ & - & - \\
\hline $\operatorname{rac}-\left.\mathrm{BAmC}\right|^{c}$ & - & 585 & 0.37 & 4.0 & 6.6 \\
\hline$(R)-\mathrm{BAmCl}^{c}$ & - & 568 & 0.29 & 7.3 & 18 \\
\hline
\end{tabular}

${ }^{a} 1.0 \times 10^{-5} \mathrm{M}$ chloroform solution. ${ }^{b}$ Amorphous sample prepared by a melt quenching method. ${ }^{c}$ Crystalline sample. ${ }^{d}$ The longest absorption maximum. eFluorescence maxima with the excitation at the longest absorption maximum. ${ }^{f}$ Absolute quantum efficiencies. ${ }^{g} k_{\mathrm{r}}=\Phi_{\mathrm{F}} / \tau_{\mathrm{av}}, k_{\mathrm{nr}}=\left(1-\Phi_{\mathrm{F}}\right) / \tau_{\mathrm{av}}, \tau_{\mathrm{av}}=$ $\Sigma \alpha_{\mathrm{i}} \tau_{\mathrm{i}}^{2} / \Sigma \alpha_{\mathrm{i}} \tau_{\mathrm{i}}$

crystal as well as the stabilization effect by intermolecular interactions. Furthermore, it should be noted that the crystal densities were determined as $1.457 \mathrm{~g} \mathrm{~cm}^{-3}$ and $1.414 \mathrm{~g} \mathrm{~cm}^{-3}$ for rac-BAmCl and $(R)-\mathrm{BAmCl}$, respectively. This result obeys the empirical Wallach's rule which states that racemic crystals tend to be denser than those of the corresponding enantiomeric crystals ${ }^{7,11}$. The crystalline structures were drastically changed after the chiral resolution.

Next, the luminescent properties of $r a c-B A m C l$ and $(R)-\mathrm{BAmCl}$ were evaluated (Fig. 2). As shown in Table 1, the absolute quantum efficiencies $\Phi_{\mathrm{F}} \mathrm{S}$ of both crystalline samples recorded were much higher than those in solution and amorphous (prepared by a melt quenching method), clearly indicating that BAmCl possesses significant CIE properties. According to our previous report, it was proposed that the excited energy in the dilute solution state was deactivated by large structura relaxation in the excited state, while in the crystalline state, intermolecular interactions restrict molecular motions. ${ }^{4 a}$ In addition, the efficient packings and ordered molecular arrangement in crystalline states drastically changed the electronic states of single molecules via electronic intermolecular interactions, which led to enhanced $\Phi_{\mathrm{F}}$ value. Similarly to this mechanism, emission enhancement should be induced by suppression of molecular motions and subsequently enhanced electronic intermolecular interactions in crystals. ${ }^{4 a}$

To gather deep insight on the relationship between crystalline structures and photophysical properties, we determined kinetic parameters including radiative $\left(k_{\mathrm{r}}\right)$ and non-radiative rate constants $\left(k_{\mathrm{nr}}\right)$, which represent the sum of rates in each process with or without emission, respectively (Fig. S14). From the
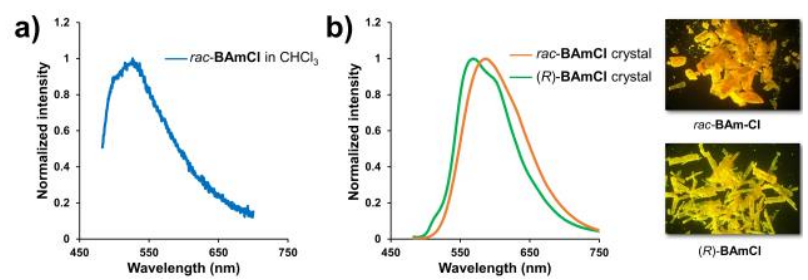

Fig. 2 Photoluminescence spectra of a) $1.0 \times 10^{-5} \mathrm{M}$ chloroform solution and b) crystalline states of rac-BAmCl and $(R)-\mathrm{BAmCl}$. Picture images were obtained under UV irradiation ( $\lambda_{\mathrm{ex}}=365 \mathrm{~nm}$, right). comparison of calculated values, the $k_{r} s$ of both crystalline samples were detected in the same range $\left(10^{8} \mathrm{~s}^{-1}\right)$, whereas the $k_{\mathrm{nr}}$ value of $(R)$-BAmCl was one order higher than that of racBAmCl. Loose packing in crystal often allows molecular tumbling followed by acceleration of non-radiative decay processes. ${ }^{12}$ Due to the lower density of the $(R)$-BAmCl crystal, it is likely that intramolecular motions could occur in the excited state, and non-radiative decay should be facilitated. The very small $\Phi_{\mathrm{F}}$ and large $k_{\mathrm{nr}}$ values in solution can support this mechanism. Further, in comparison to $(R)$-BAmCl, slight reduction of $k_{\mathrm{r}}$ and red shift of the emission band were observed from rac-BAmCl. These results can be explained by the tight packing. Electronic states can be stabilized by intermolecular interactions in condensed states, whereas concentration quenching should be simultaneously caused. Therefore, the emission band with shorter lifetime in the longer wavelength region could be obtained from rac-BAmCl. In summary, it can be said that $\mathrm{BAmCl}$ basically has crystalline-state luminescent property. Owing to the unique molecular structure, intermolecular interactions, which tend to induce concentration quenching, can be disturbed, and intense emission can be obtained even in crystal. Furthermore, the luminescent properties including emission intensity and color are sensitive in the degree of molecular tumbling and molecular arrangements. As a consequence, not only $\mathrm{CIE}$ but also emission peak shifts are obtained.

Additionally, circularly polarized luminescence (CPL) properties were also examined. In solution, we were not able to obtain mirror imaging spectra because BAmCl enantiomers were intrinsically non-fluorescent in the solution states (Fig. S19). In solid, obvious mirror image CPL signals were detected in the emission region (Fig. S20). However, CPL intensity and dissymmetry factor, $g_{\text {lum }}=2\left(l_{\text {left }}-I_{\text {right }}\right) /\left(l_{\text {left }}+I_{\text {right }}\right)\left(l_{\text {left }}, I_{\text {right }}: \mathrm{PL}\right.$ intensities of left and right-handed $\mathrm{CPL}$, respectively) were very low. Before solid-state CPL measurements, the crystal samples were highly compressed to form $\mathrm{KBr}$ tablets and critical decrease in crystallinities was induced. This treatment might decrease sensitivity for detecting the chiroptical properties of BAmCl in the solid states.

The thermogravimetric analysis (TGA) was conducted under $\mathrm{N}_{2}$ atmosphere to compare thermal stability of the racemic and chiral crystals (Fig. S15 and S16). The initial decomposition temperature $\left(T_{\mathrm{i}}\right)$ of $(R)$-BAmCl $\left(155^{\circ} \mathrm{C}\right)$ was much lower than that of rac-BAmCl $\left(227^{\circ} \mathrm{C}\right)$. It is likely that molecular motions can vigorously occur by heating because of lower density packing in the crystal of $(R)$-BAmCl, and pyrolysis should proceed. Next, to investigate phase transition processes in solid, differential scanning calorimetry (DSC) measurements were performed (Fig. S17). In both crystals, the clear endothermic peaks attributed to the melting points were observed in the heating processes $\left(T_{\mathrm{m}, \text { onset }}=174{ }^{\circ} \mathrm{C}\right.$ for rac- $\mathrm{BAmCl} ; T_{\mathrm{m} \text {,onset }}=$ $139{ }^{\circ} \mathrm{C}$ for $\left.(R)-\mathrm{BAmCl}\right)$. From the crystalline material involving a boron chirality center, it was reported that racemization can occur via the $\mathrm{N}-\mathrm{B}$ bond dissociation. ${ }^{13}$ Therefore, we also examined influence on the chirality with the $(R)$-BAmCl crystal by melting (Fig. S18). Accordingly, when the crystalline sample was heated at $120^{\circ} \mathrm{C}$, which is below $T_{\mathrm{m}}$, for $20 \mathrm{~min}$, the single 
peak corresponded to $(R)$-BAmCl was detected in the chiral HPLC profile, meaning that racemization hardly occurred. In contrast, after heating at $150{ }^{\circ} \mathrm{C}$ for $20 \mathrm{~min}$, the molten sample was obtained, and the additional broad peak corresponding to the $(S)$-enantiomer was detected with the slight shoulder caused by pyrolysis. Surprisingly, according to the peak integral ratios, it was shown that both enantiomers exist with almost same proportions $\left(I_{R} / I_{S}=1.02, I\right.$ : Integration of peak area for each enantiomer). This result clearly indicates that racemization completely proceeded at the molten liquid state. ${ }^{14}$ To the best our knowledge, this is the first example to induce racemization at the boron stereogenic center in solid without any solvents. This multi temperature-responsive ability based on chiroptical information and luminescent signal change would be applicable for extensive usages, such as chiroptical sensing, optical displays and information storage.

In conclusion, we demonstrate in this research that chiral resolution of flexible fused-skeleton having a stereogenic boron center should be a valid strategy for creating luminescent polymorphic materials. The structural analyses for racemic crystal rac-BAmCl and homochiral crystal $(R)$-BAmCl reveal that their molecular arrangements are totally different: the molecules in rac-BAmCl formed dense dimeric structures between the $(R)$ - and (S)-enantiomers, whereas $(R)$ enantiomers in $(R)$-BAmCl loosely stacked in helical-shaped molecular motifs. These structural differences have a significant influence on the crystalline-state emissive properties and these crystals displayed distinct different emission colors. Interestingly, the heat-initiated homogeneous racemization without any solvents and catalysts was observed in the molten state of crystal $(R)-\mathbf{B A m C l}$. This dynamic stereochemical behavior in homogenous media would be a promising scaffold for constructing the solid-state stimuli-responsive materials.

This work was partially supported by an Izumi Science and Technology Foundation (for M.G.) and a Grant-in-Aid for Young Scientists (for M.G.) (JSPS KAKENHI Grant numbers 20K15334) and Grant-in-Aid for ScientificResearch (B) (JSPS KAKENHI Grant numbers 17H03067) and (A) (JSPS KAKENHI Grant numbers 17H01220) and a Grant-in-Aid for Scientific Research on Innovative Areas "New Polymeric Materials Based on ElementBlocks (No.2401)" (JSPS KAKENHI Grant Number 24102013) and a Challenging Research (Pioneering) (JSPS KAKENHI Grant Number 18H05356).

\section{Conflicts of interest}

There are no conflicts to declare.

\section{Notes and references}

1 (a) Y. Liu, K.-R. Wang, D.-S. Guo and B.-P. Jiang, Adv. Funct. Mater., 2009, 19, 2230-2235. (b) S. Saotome, K. Suenaga, K. Tanaka and Y. Chujo, Mater. Chem. Front., 2020, 4, 17811788. (c) K. Li, Y. Chen, W. Lu, N. Zhu and C.-M. Che, Chem. Eur. J., 2011, 17, 4109-4112.

2 (a) S.-W. Zhang and T. M. Swager, J. Am. Chem. Soc., 2003, 125, 3420-3421; (b) L. Basabe-Desmonts, D. N. Reinhoudt and M. Crego-Calama, Chem. Soc. Rev., 2007, 36, 993-1017.
3 (a) Y. Chujo and K. Tanaka, Bull. Chem. Soc. Jpn., 2015, 88, 633-643; (b) M. Gon, K. Tanaka and Y. Chujo, Polym. J., 2017, 50, 109-126; (c) K. Tanaka and Y. Chujo, Polym. J., 2020, 52, 555-566; (d) M. Gon, K. Tanaka and Y. Chujo, Bull. Chem. Soc. Jpn., 2019, 92, 7-18.

4 (a) S. Ohtani, M. Gon, K. Tanaka and Y. Chujo, Chem. - Eur. J. 2017, 23, 11827-11833; (b) S. Ohtani, M. Gon, K. Tanaka and Y. Chujo, Macromolecules, 2019, 52, 3387-3393; (c) S. Ohtani, M. Nakamura, M. Gon, K. Tanaka and Y. Chujo, Chem. Commun., 2020, 56, 6575-6578; (d) S. Ohtani, M. Gon, K. Tanaka and Y. Chujo, Crystals 2020, 10, 615

5 (a) Y. Dong, J. W. Y. Lam, A. Qin, Z. Li, J. Sun, H. H.-Y. Sung, I. D. Williams and B. Z. Tang, Chem. Commun., 2007, 40-42; (b) P. Galer, R. C. Korošec, M. Vidmar and B. Šket, J. Am. Chem. Soc., 2014, 136, 7383-7394. (c) T. Han, X. Feng, D. Chen and Y. Dong, J. Mater. Chem. C, 2015, 3, 7446-7454.

6 (a) D. Gentili, M. Gazzano, M. Melucci, D. Jones and M. Cavallini, Chem. Soc. Rev., 2019, 48, 2502-2517. (b) Z. He, L. Zhang, J. Mei, T. Zhang, J. W. Y. Lam, Z. Shuai, Y. Q. Dong and B. Z. Tang, Chem. Mater., 2015, 27, 6601-6607. (c) G. Zhang, J. Lu, M. Sabat and C. L. Fraser, J. Am. Chem. Soc., 2010, 132, 2160-2162. (d) X. Gu, J. Yao, G. Zhang, Y. Yan, C. Zhang, Q. Peng, Q. Liao, Y. Wu, Z. Xu, Y. Zhao, H. Fu and D. Zhang, Adv. Funct. Mater., 2012, 22, 4862-4872.

7 (a) O. Wallach Justus Liebigs Ann. Chem., 1895, 286, 90-143 (b) T. Friščić, L. Fábián, J. C. Burley, D. G. Reid, M. J. Duer and W. Jones, Chem. Commun., 2008, 1644-1646.

8 (a) A. Wakamiya, T. Taniguchi and S. Yamaguchi, Angew. Chem. Int. Ed., 2006, 45, 3170-3173; (b) Y. Adachi, Y. Ooyama, Y. Ren, X. Yin, F. Jäkle and J. Ohshita, Polym. Chem., 2018, 9, 291-299; (c) M. Hesari, S. M. Barbon, V. N. Staroverov, Z. Ding and J. B. Gilroy, Chem. Commun., 2015, 51, 3766-3769; (d) J. Yoshino, N. Kano and T. Kawashima, J. Org. Chem., 2009, 74, 7496-7503; (e) A. Sundararaman, M. Victor, R. Varughese and F. Jäkle, J. Am. Chem. Soc., 2005, 127, 13748-13749; (f) M. Urban, K. Durka, P. Jankowski, J. Serwatowski and S. Luliński, J. Org. Chem., 2017, 82, 82348241.

9 (a) A. Haefele, C. Zedde, P. Retailleau, G. Ulrich and R. Ziessel, Org. Lett., 2010, 12, 1672-1675; (b) V. G. Jiménez, F. M. F. Santos, S. Castro-Fernández, J. M. Cuerva, P. M. P. Gois, U. Pischel and A. G. Campaña, J. Org. Chem., 2018, 83, 14057-14062.

10 S. Varughese, J. Mater. Chem. C, 2014, 2, 3499-3516.

11 M. Jin, T. Seki and H. Ito, Chem. Commun., 2016, 52, 80838086.

12 (a) Y. Akune, R. Hirosawa, N. Endo, S. Hatano, T. Hosokai, H. Sato and S. Matsumoto, CrystEngComm, 2017, 19, 19471952. (b) T. Hinoue, Y. Mizobe, I. Hisaki, M. Miyata and N. Tohnai, Chem. Lett., 2008, 37, 642-643. (c) I. Hisaki, E. Kometani, H. Shigemitsu, A. Saeki, S. Seki, N. Tohnai and M. Miyata, Cryst. Growth \& Des., 2011, 11, 5488-5497.

13 (a) M. Oki and M. Ohira, Bull. Chem. Soc. Jpn., 1984, 57, 3117-3121; (b) S. Toyota, T. Hakamata, N. Nitta and F. Ito, Chem. Lett., 2004, 33, 206-207; (c) S. Schlecht, W. Frank and M. Braun, Beilstein J. Org. Chem., 2011, 7, 615-621.

14 H. Wu and A. West, Crystal Growth \& Design, 2011, 11, 3366-3374. 
Supporting Information

\section{Facile Strategy for Obtaining Luminescent Polymorphs Based on Chirality of Boron-Fused Azomethine Complex}

Shunsuke Ohtani, Yusuke Takeda, Masayuki Gon, Kazuo Tanaka* and Yoshiki Chujo

Department of Polymer Chemistry, Graduate School of Engineering, Kyoto University Katsura, Nishikyo-ku, Kyoto 615-8510, Japan

E-mail: tanaka@poly.synchem.kyoto-u.ac.jp

Contents:

page

General

Materials

Synthesis of AmCl

Synthesis of BAmCl

Chiral resolution of racemate $\mathbf{B A m C l}$

Circular dichroism (CD) study

Single-crystal X-ray structure analysis of rac-BAmCl and $(R)$-BAmCl

PL lifetime decay curves

Thermogravimetric analysis (TGA)

Differential scanning calorimetric (DSC) analysis

Racemization study of $(R)$-BAmCl 


\section{General}

${ }^{1} \mathrm{H}(400 \mathrm{MHz}),{ }^{13} \mathrm{C}(100 \mathrm{MHz}){ }^{11} \mathrm{~B}(128 \mathrm{MHz})$ NMR spectra were recorded on JEOL JNM-AL400 or JNMEX400 spectrometers. Samples were analyzed in $\mathrm{CDCl}_{3}$ and DMSO- $\mathrm{d}_{6}$. The chemical shift values were expressed relative to tetramethylsilane (TMS) for ${ }^{1} \mathrm{H}$ and ${ }^{13} \mathrm{C}$ NMR as an internal standard in $\mathrm{CDCl}_{3}$ and $\mathrm{BF}_{3} \cdot \mathrm{OEt}_{2}$ for ${ }^{11} \mathrm{~B}$ NMR as a capillary standard. Analytical thin-layer chromatography (TLC) was performed with silica gel 60 Merck F254 plates. Column chromatography was performed with Wakogel ${ }^{\circledR}$ C-300 silica gel. High-resolution mass (HRMS) spectrometry was performed at the Technical Support Office (Department of Synthetic Chemistry and Biological Chemistry, Graduate School of Engineering, Kyoto University), and the HRMS spectra were obtained on a Thermo Fisher Scientific EXACTIVE spectrometer for electrospray ionization (ESI). UV-vis-NIR absorption spectra were recorded on a SHIMADZU UV-3600 spectrophotometer, and samples were analyzed at room temperature. Photoluminescence (PL) spectra were measured on a HORIBA JOBIN YVON Fluoromax-4P spectrofluorometer. Absolute PL quantum efficiency was measured on a Hamamatsu Photonics Quantaurus-QY Plus C13534-01. The PL lifetime measurement was performed on a Horiba FluoroCube spectrofluorometer system; excitation was carried out using a UV diode laser (NanoLED $375 \mathrm{~nm}$ ). X-ray crystallographic analysis was carried out by Rigaku R-AXIS RAPID-F imaging plate diffractometer with graphite-monochromated MoK $\alpha$ radiation and Rigaku Saturn 724+ with MicroMax-007HF CCD diffractometer with Varimax Mo optics using graphite-monochromated MoK $\alpha$ radiation. The analysis was carried out with direct methods (SHELX-2014/7) using Yadokari-XG. The program Mercury 3.3.1 was used to generate the X-ray structural diagram. Thermogravimetric analyses (TGA) were recorded on a Hitachi High-Tech Science Corp. STA7200RV. Differential scanning calorimetry (DSC) was recorded on a Hitachi High-Tech Science Corp. DSC7020. Circular dichroism (CD) spectra were measured on a JASCO J-820 spectropolarimeter. Circularly polarized luminescence (CPL) spectra were recorded on a JASCO CPL-200S spectrofluoropolarimeter. Solid-state CPL spectra were measured for $(R)$ - and $(S)$-BAmCl $(0.5 \mathrm{mg})$ mixed with $\mathrm{KBr}(150 \mathrm{mg})$. Tablets (diameter: $10 \mathrm{~mm},(R)$ - or $(S)$ BAmCl $/ \mathrm{KBr}$ ) were prepared using a tablet forming machine ( $48.2 \mathrm{kN}$, press time: $3 \mathrm{~min})$. Chiral high performance liquid chromatography (HPLC) was performed with YMC CHIRAL ART Amylose-SA $(5 \mu \mathrm{m}) 250 \times 20 \mathrm{mml} . \mathrm{D}$. and SHIMADZU Prominence Modular HPLC system. Specific rotations $\left([\alpha]^{\mathrm{t}} \mathrm{D}\right)$ were measured with a Rudolph Research AUTOPOL IV Automatic Polarimeter. 


\section{Materials}

Commercially available compounds used without purification:

2-Amino-5-chlorophenol (Tokyo Chemical Industry Co, Ltd.)

4-(Diethylamino)salicylaldehyde (Tokyo Chemical Industry Co, Ltd.)

Boron trifluoride diethyl etherate $\left(\geq 46 \% \mathrm{BF}_{3}\right.$ basis) $\left(\mathrm{BF}_{3} \cdot \mathrm{OEt}_{2}\right)$ (Sigma-Aldrich Co. LLC.)

Commercially available solvents:

EtOH (Wako Pure Chemical Industries, Ltd.), $\mathrm{CHCl}_{3}$ (Wako Pure Chemical Industries, Ltd.), $n$-hexane (Wako Pure Chemical Industries, Ltd.) and $\mathrm{CH}_{2} \mathrm{Cl}_{2}$ (Wako Pure Chemical Industries, Ltd.) were used without further purification. Deoxidized grade toluene (Wako Pure Chemical Industries, Ltd.) were used without further purification. Triethylamine (Kanto Chemical Co., Inc.) was purified by passage through solvent purification columns under argon pressure. 


\section{Synthetic Procedures and Characterization}

\section{$\underline{\text { Synthesis of AmCl }}$}
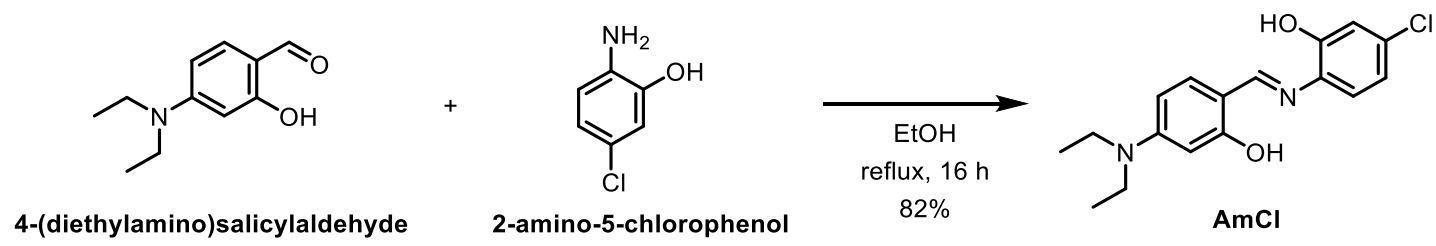

Scheme S1. Synthesis of AmCl.

2-Amino-5-chlorophenol $(0.37 \mathrm{~g}, 2.59 \mathrm{mmol})$ was dissolved in $20 \mathrm{~mL}$ of EtOH. 4(Diethylamino)salicylaldehyde $(0.50 \mathrm{~g}, 2.59 \mathrm{mmol})$ was added to the solution and the reaction mixture was stirred at reflux temperature for $16 \mathrm{~h}$. During course of the reaction, the product was precipitated from the reaction mixture. After cooling to room temperature, the resulting mixture was poured into water. The precipitation collected by filtration was dried in vacuo to give $\mathbf{A m C l}$ as an orange solid (0.68 g, 82\%). ${ }^{1} \mathrm{H} \mathrm{NMR}\left(\mathrm{CDCl}_{3}, 400 \mathrm{MHz}\right), \delta(\mathrm{ppm})$ : $8.40(\mathrm{~s}, 1 \mathrm{H}), 7.19(\mathrm{~d}, J=8.8 \mathrm{~Hz}, 1 \mathrm{H}), 7.00-6.98(\mathrm{~m}, 2 \mathrm{H}), 6.89(\mathrm{dd}, J=8.3,2.2 \mathrm{~Hz}, 1 \mathrm{H}), 6.28(\mathrm{dd}, J=8.8,2.4 \mathrm{~Hz}$, $1 \mathrm{H}), 6.19(\mathrm{~d}, J=2.4 \mathrm{~Hz}, 1 \mathrm{H}), 3.42(\mathrm{q}, J=7.1 \mathrm{~Hz}, 4 \mathrm{H}), 1.22(\mathrm{t}, J=7.1 \mathrm{~Hz}, 6 \mathrm{H}) .{ }^{13} \mathrm{C}$ NMR $\left(\mathrm{DMSO}-\mathrm{d}_{6}, 100 \mathrm{MHz}\right)$, $\delta(\mathrm{ppm}): 164.5,159.8,151.6,151.2,134.6,133.9,129.4,119.9,119.3,115.8,108.9,103.7,97.0,43.8,12.5$. HRMS (ESI): Calcd for $[\mathrm{M}+\mathrm{H}]^{+}, 319.1208$; Found, $\mathrm{m} / \mathrm{z}$ 319.1203. Elemental analysis calcd. for $\mathrm{C}_{17} \mathrm{H}_{19} \mathrm{ClN}_{2} \mathrm{O}_{2}$ : $\mathrm{C}, 64.05$; H, 6.01; N, 8.79. Found: C, 64.10; H, 5.91; N, 8.89. 

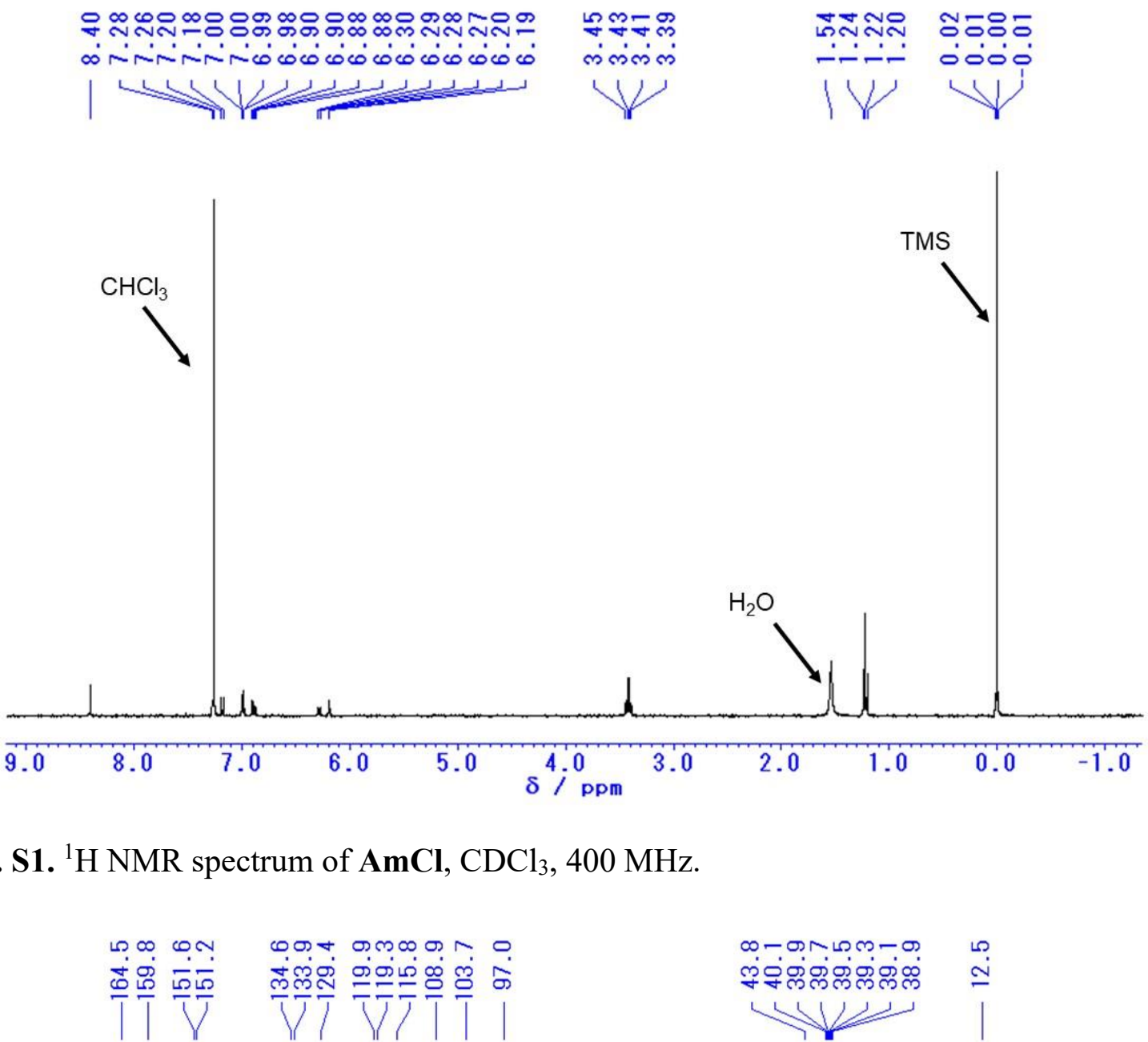

Fig. S1. ${ }^{1} \mathrm{H}$ NMR spectrum of $\mathbf{A m C l}, \mathrm{CDCl}_{3}, 400 \mathrm{MHz}$.
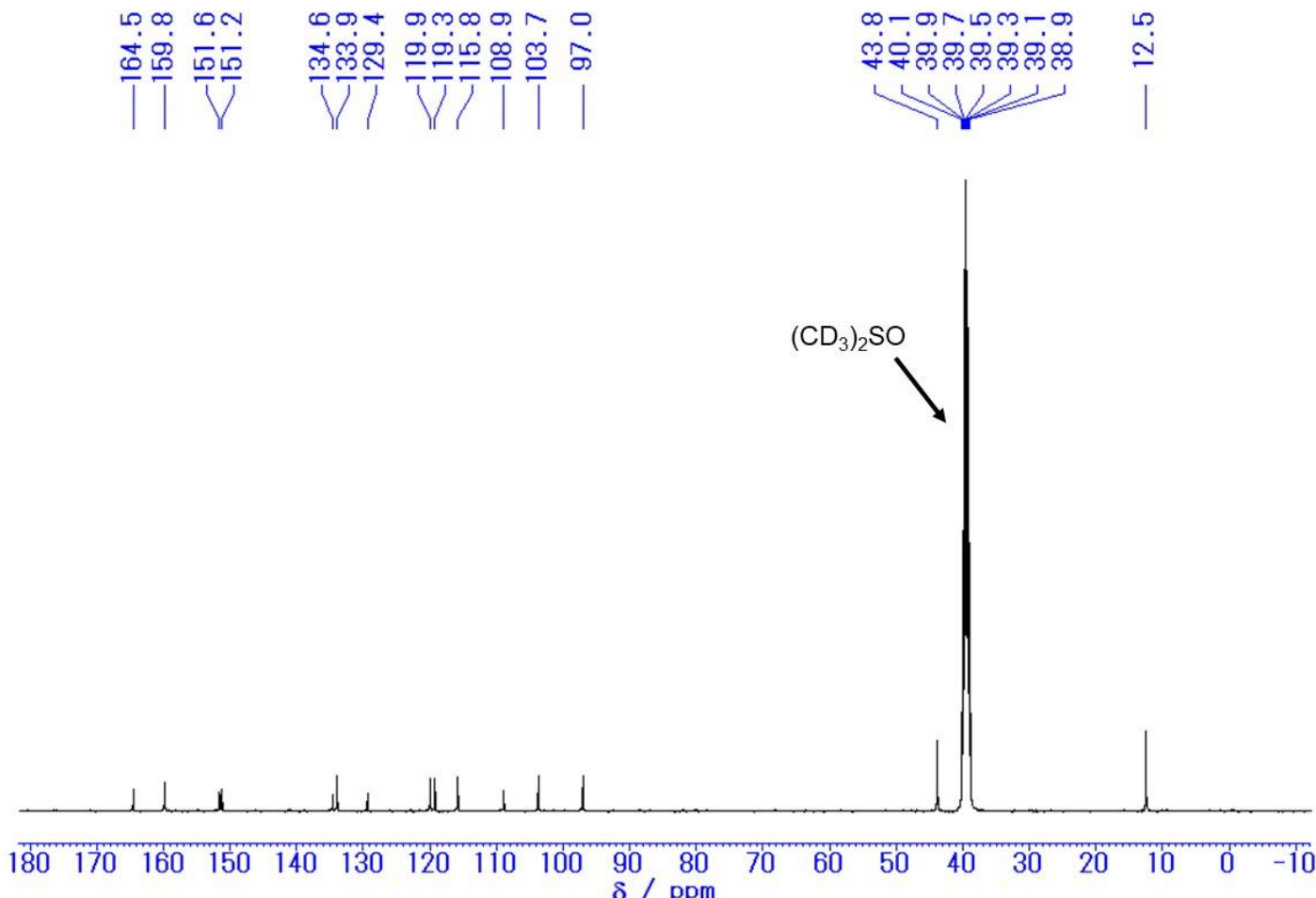

Fig. S2. ${ }^{13} \mathrm{C}$ NMR spectrum of AmCl, DMSO-d 6 , $100 \mathrm{MHz}$. 


\section{Synthesis of BAmCl}<smiles>CCN(CC)c1ccc(/C=N/c2ccc(Cl)cc2O)c(O)c1</smiles>

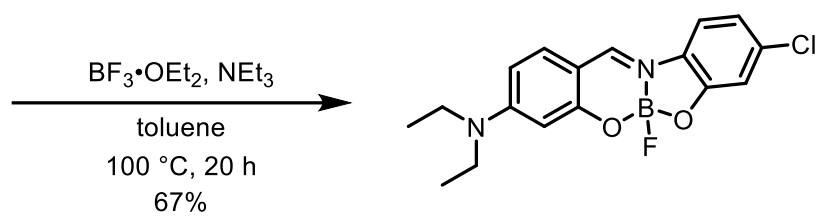

Scheme S2. Synthesis of BAmCl.

Am-Cl $(0.40 \mathrm{~g}, 1.25 \mathrm{mmol})$ was dissolved in $13 \mathrm{~mL}$ of dry toluene under Ar atmosphere at room temperature and triethylamine $(4 \mathrm{~mL})$ was then added to the solution. $\mathrm{BF}_{3} \cdot \mathrm{OEt}_{2}(3 \mathrm{~mL})$ was added dropwise to the solution and the reaction mixture was stirred at $100{ }^{\circ} \mathrm{C}$ for $20 \mathrm{~h}$. After cooling to room temperature, the resulting mixture was quenched by EtOH and concentrated by a rotary evaporator. The residue was purified by chromatography on silica gel with $\mathrm{CH}_{2} \mathrm{Cl}_{2}$ and dissolved in small amount of $\mathrm{CHCl}_{3}$, and the product was reprecipitated from hexane to give $\mathbf{B A m C l}$ as an orange solid $(0.29 \mathrm{~g}, 67 \%)$. $\mathrm{R}_{\mathrm{f}}=0.79\left(\mathrm{CH}_{2} \mathrm{Cl}_{2}\right)$. HRMS (ESI): Calcd for $[\mathrm{M}+\mathrm{Na}]^{+}$, 347.1128; Found, $\mathrm{m} / \mathrm{z}$ 347.1121. Elemental analysis calcd. for $\mathrm{C}_{17} \mathrm{H}_{17} \mathrm{BClFN}_{2} \mathrm{O}_{2}$ : C, 58.91; H, 4.94; N, 8.08. Found: C, 58.84; H, 4.94; N, 8.07.

\section{$\underline{\text { Racemic BAmCl: }}$}

${ }^{1} \mathrm{H} \mathrm{NMR}\left(\mathrm{CDCl}_{3}, 400 \mathrm{MHz}\right), \delta(\mathrm{ppm}): 8.25(\mathrm{~s}, 1 \mathrm{H}), 7.31(\mathrm{~d}, J=9.3 \mathrm{~Hz}, 1 \mathrm{H}), 7.22(\mathrm{~d}, J=8.3 \mathrm{~Hz}, 1 \mathrm{H})$, $7.06(\mathrm{~d}, J=2.0 \mathrm{~Hz}, 1 \mathrm{H}), 6.86(\mathrm{dd}, J=8.4,2.0 \mathrm{~Hz}, 1 \mathrm{H}), 6.43(\mathrm{dd}, J=9.1,2.5 \mathrm{~Hz}, 1 \mathrm{H}), 6.37(\mathrm{~d}, J=2.4 \mathrm{~Hz}$, 1H), $3.47(\mathrm{~m}, 4 \mathrm{H}), 1.25(\mathrm{t}, J=7.1 \mathrm{~Hz}, 6 \mathrm{H}) .{ }^{11} \mathrm{~B} \mathrm{NMR}\left(\mathrm{CDCl}_{3}, 128 \mathrm{MHz}\right), \delta(\mathrm{ppm}): 4.27$ (d, $\left.J=38 \mathrm{MHz}\right)$. ${ }^{13} \mathrm{C} \mathrm{NMR}\left(\mathrm{CDCl}_{3}, 100 \mathrm{MHz}\right), \delta$ (ppm): 160.1, 156.4, 155.9, 148.1, 133.8, 133.4, 129.5, 119.4, 114.7, 113.4 , $108.6,107.4,99.5,45.2,12.7$.

\section{Enantiomeric BAmCl-fr1 $((R)$-BAmCl):}

$[\alpha]^{23} \mathrm{D}=+1226.5\left(c 0.1, \mathrm{CHCl}_{3}\right)$

${ }^{1} \mathrm{H}$ NMR $\left(\mathrm{CDCl}_{3}, 400 \mathrm{MHz}\right), \delta(\mathrm{ppm}): 8.25(\mathrm{~s}, 1 \mathrm{H}), 7.31(\mathrm{~d}, J=9.0 \mathrm{~Hz}, 1 \mathrm{H}), 7.22(\mathrm{~d}, J=8.3 \mathrm{~Hz}, 1 \mathrm{H})$, $7.06(\mathrm{~d}, J=1.9 \mathrm{~Hz}, 1 \mathrm{H}), 6.87(\mathrm{dd}, J=8.6,2.2 \mathrm{~Hz}, 1 \mathrm{H}), 6.44(\mathrm{dd}, J=9.0,2.4 \mathrm{~Hz}, 1 \mathrm{H}), 6.37(\mathrm{~d}, J=2.4 \mathrm{~Hz}$, 1H), $3.47(\mathrm{~m}, 4 \mathrm{H}), 1.25(\mathrm{t}, J=7.1 \mathrm{~Hz}, 6 \mathrm{H}) .{ }^{11} \mathrm{~B} \mathrm{NMR}\left(\mathrm{CDCl}_{3}, 128 \mathrm{MHz}\right), \delta(\mathrm{ppm}): 4.27$ (d, $\left.J=38 \mathrm{MHz}\right)$.

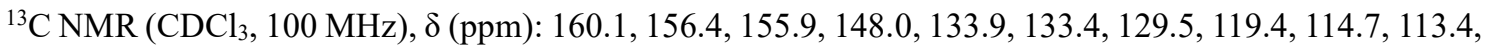
108.7, 107.4, 99.6, 45.2, 12.7.

\section{Enantiomeric BAmCl-fr2 $((S)-\mathbf{B A m C l})$ :}

$$
[\alpha]^{23}{ }_{\mathrm{D}}=-1244.6\left(c \quad 0.1, \mathrm{CHCl}_{3}\right)
$$

The NMR spectra of BAmCl-fr2 were the same with BAmCl-fr1. 


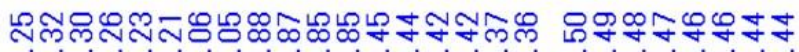

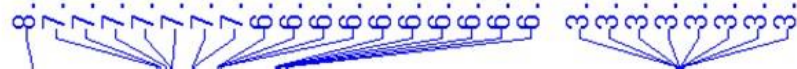
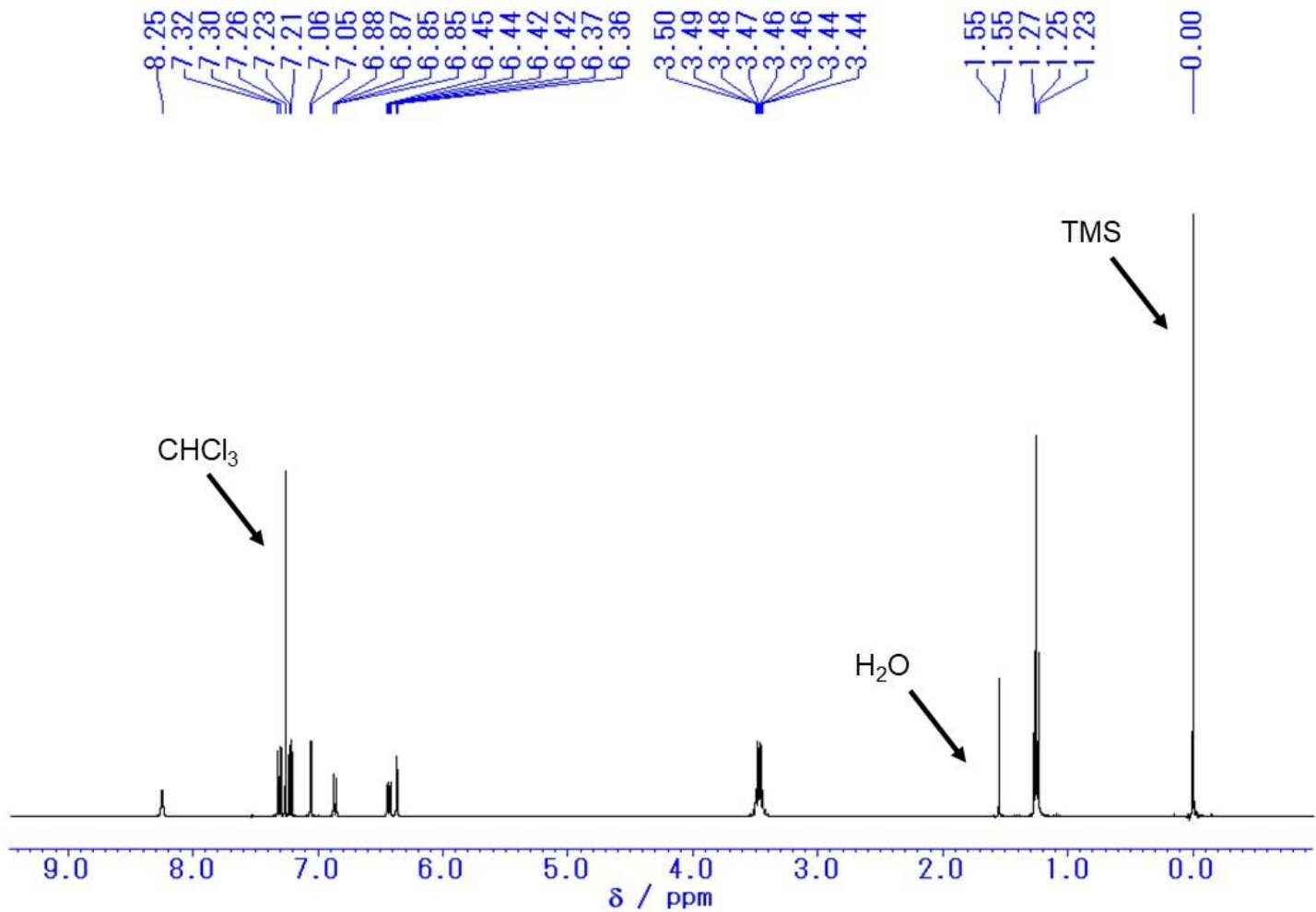

Fig. S3. ${ }^{1} \mathrm{H}$ NMR spectrum of racemic BAmCl, $\mathrm{CDCl}_{3}, 400 \mathrm{MHz}$.

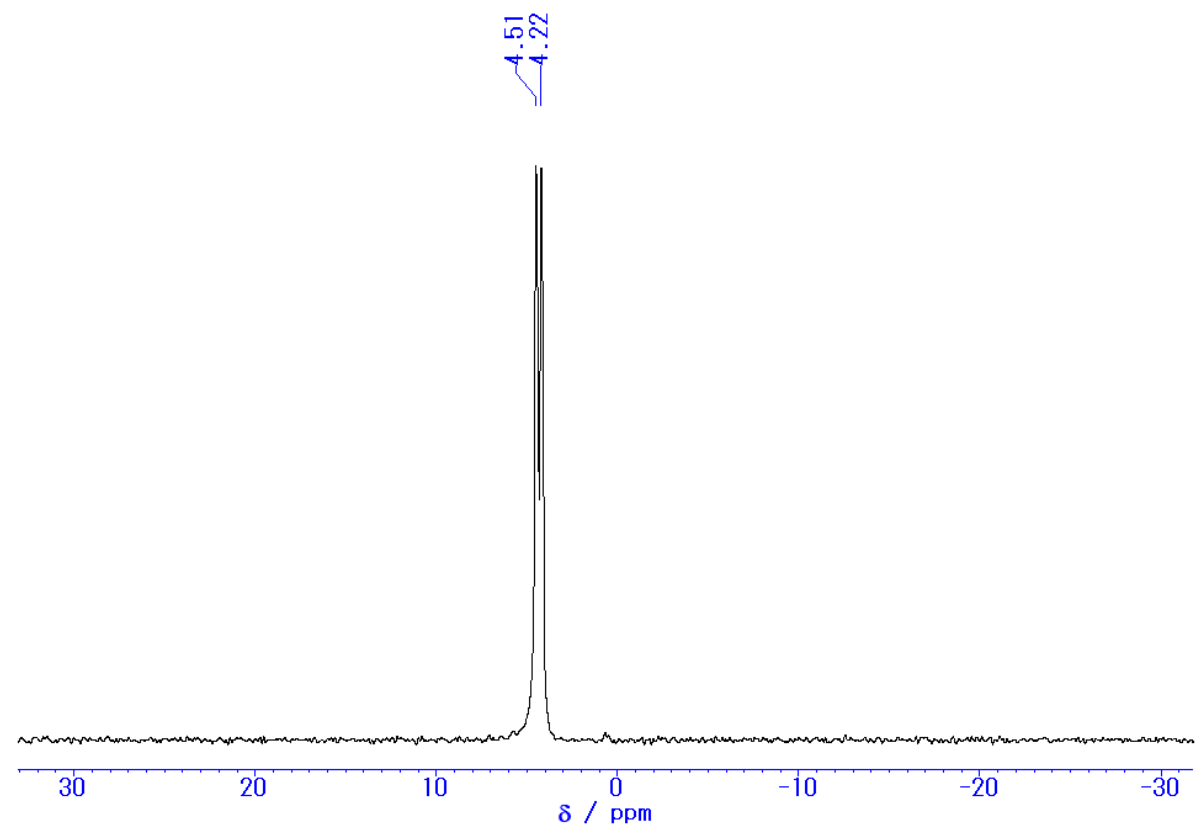

Fig. S4. ${ }^{11} \mathrm{~B}$ NMR spectrum of racemic BAmCl, $\mathrm{CDCl}_{3}, 128 \mathrm{MHz}$. 


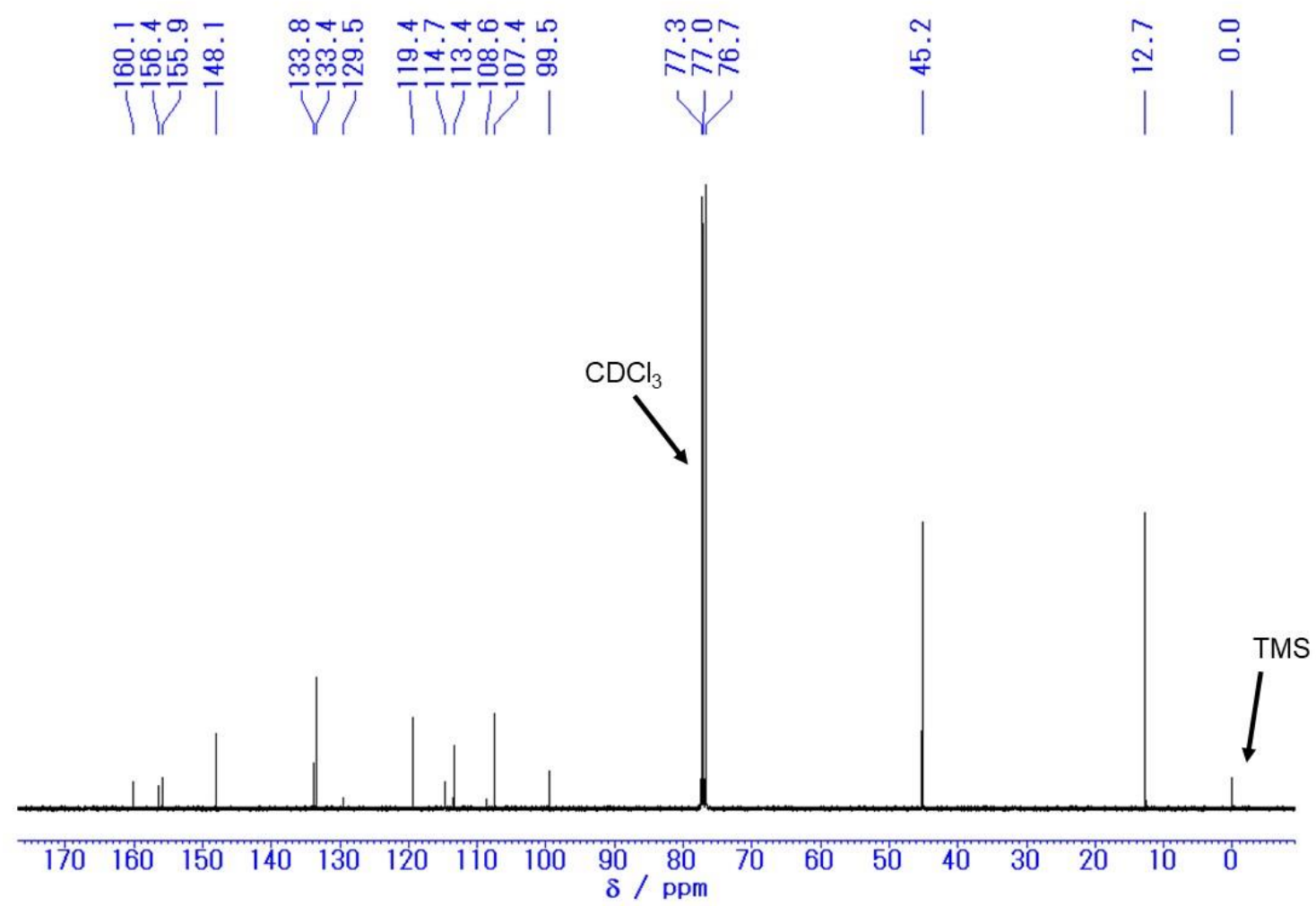

Fig. S5. ${ }^{13} \mathrm{C}$ NMR spectrum of racemic $\mathbf{B A m C l}, \mathrm{CDCl}_{3}, 100 \mathrm{MHz}$. 


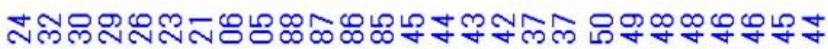

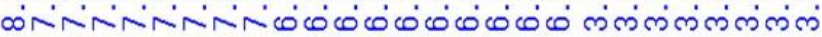
$\left.1 \mathrm{~L}^{\prime}\right)$

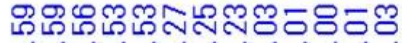

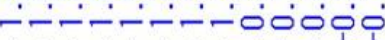

1) 13

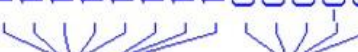

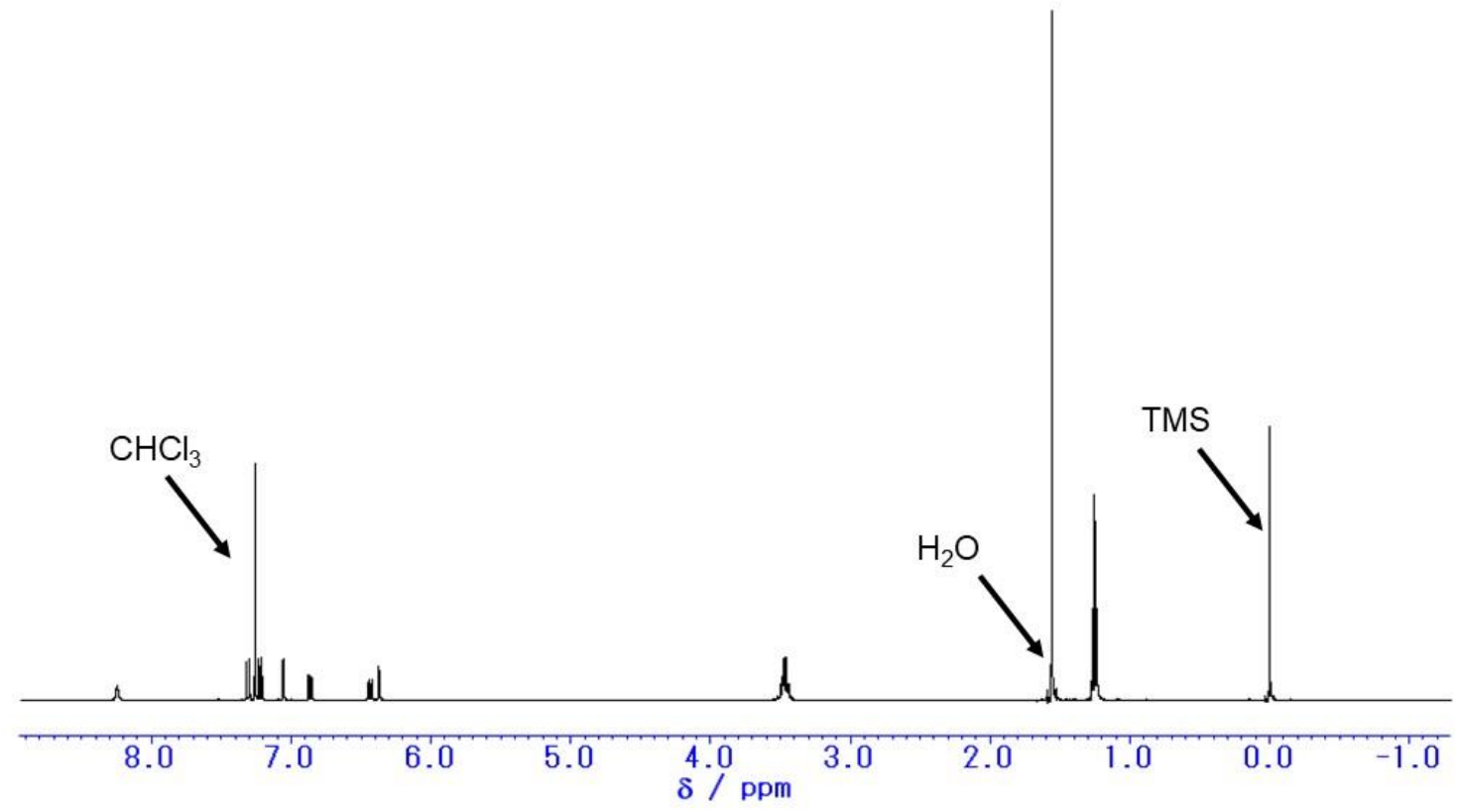

Fig. S6. ${ }^{1} \mathrm{H} \mathrm{NMR}$ spectrum of enantiomeric BAmCl-fr1 $((R)-\mathbf{B A m C l}), \mathrm{CDCl}_{3}, 400$ $\mathrm{MHz}$.

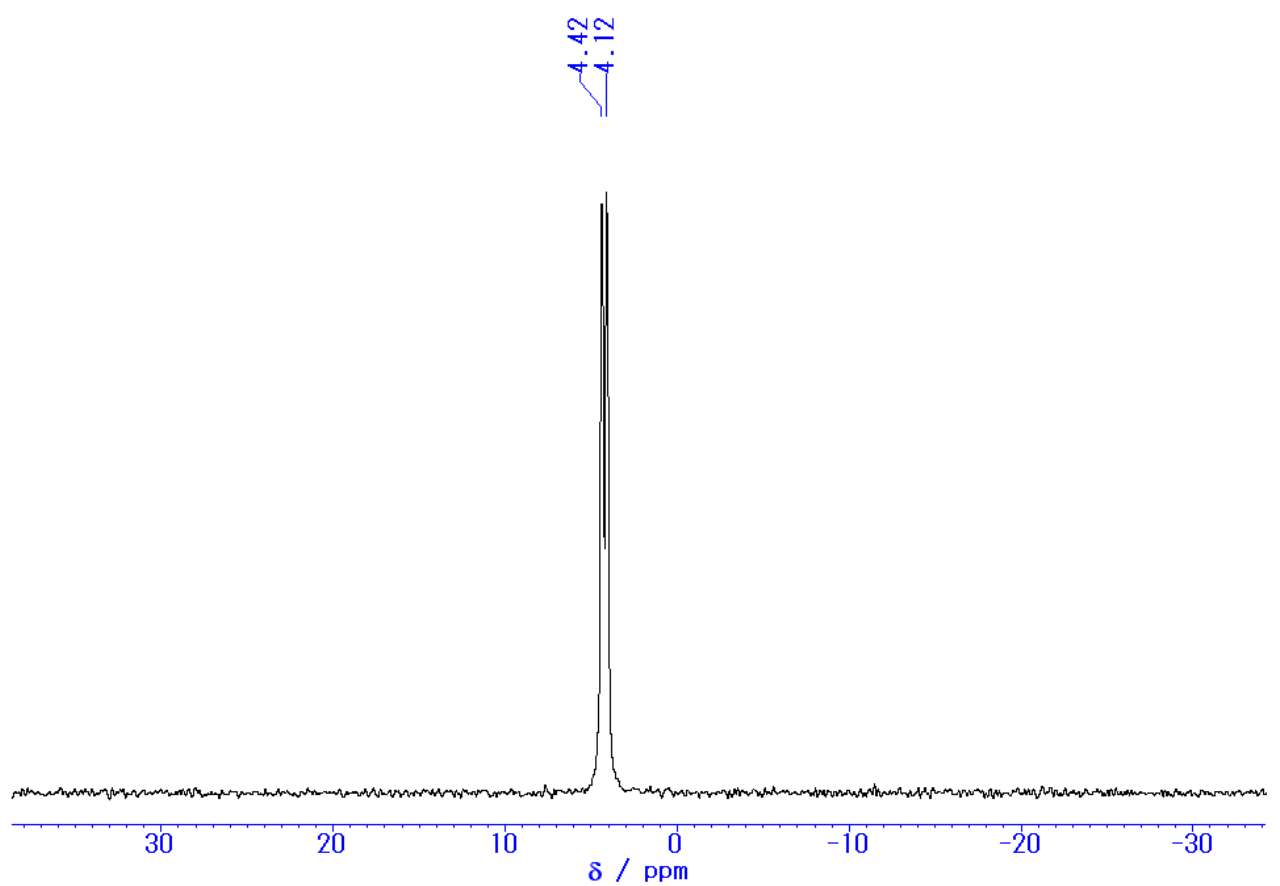

Fig. S7. ${ }^{11} \mathrm{~B}$ NMR spectrum of enantiomeric BAmCl-fr1 $\left((R)\right.$-BAmCl), $\mathrm{CDCl}_{3}, 128$ $\mathrm{MHz}$. 


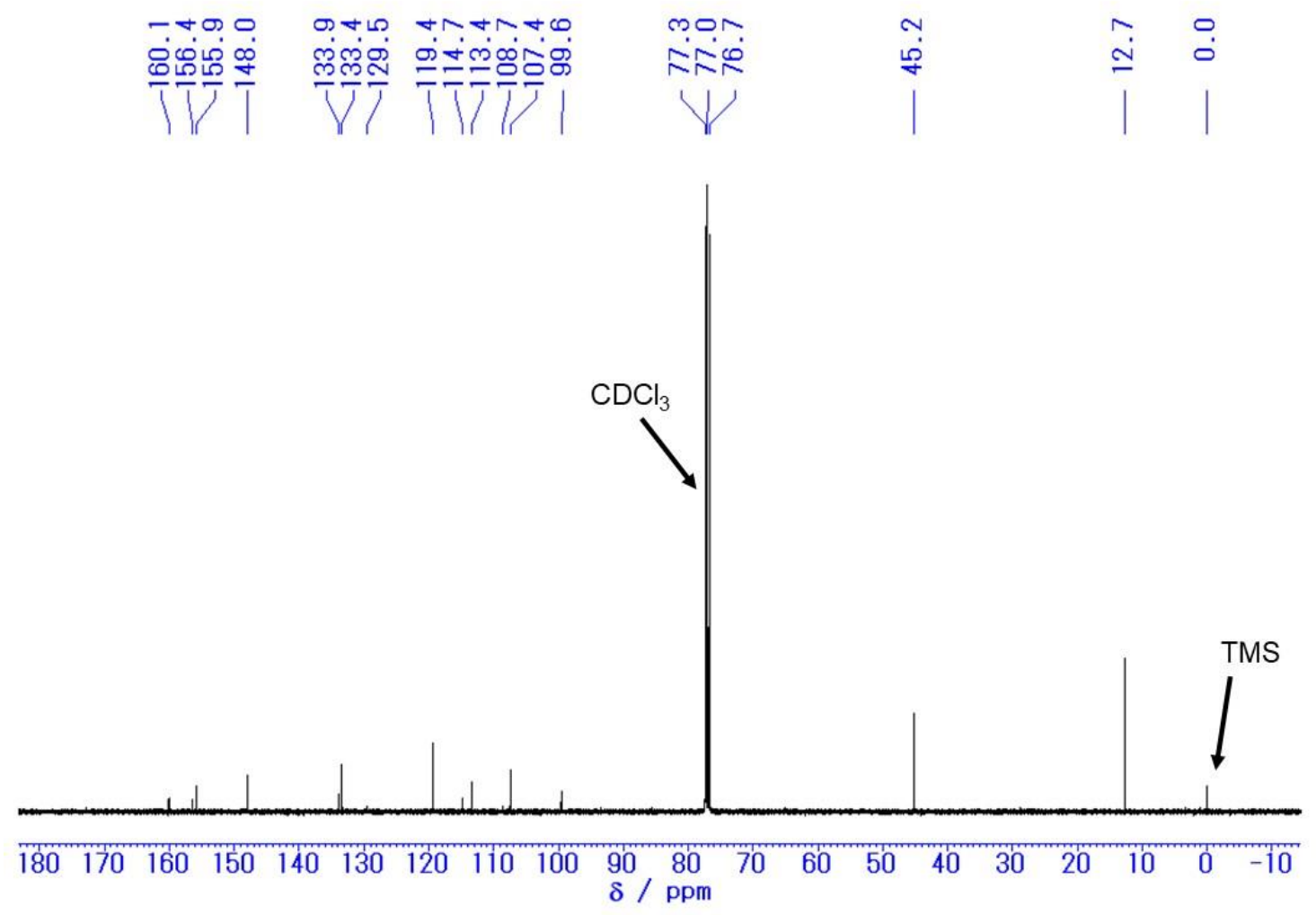

Fig. S8. ${ }^{13} \mathrm{C}$ NMR spectrum of enantiomeric BAmCl-fr1 $1((R)-\mathbf{B A m C l}), \mathrm{CDCl}_{3}, 100$ MHz. 


\section{Chiral resolution of racemate $\mathrm{BAmCl}$}

Table S1. Analysis condition of resolution by chiral HPLC

\begin{tabular}{|l|l|}
\hline Column & YMC CHIRAL ART Amylose-SA $(5 \mu \mathrm{m}) 250 \times 20 \mathrm{mml} . \mathrm{D}$. \\
Eluent & $n$-hexane $/ \mathrm{THF}(\mathrm{v} / \mathrm{v}=1 / 3)$ \\
Flow rate & $3.5 \mathrm{~mL} / \mathrm{min}$ \\
Detection & $\mathrm{UV}$ at $250 \mathrm{~nm}$ \\
Injection & $3.0 \mathrm{~mL}(6.7 \mathrm{mg} / \mathrm{mL})$ \\
Retention Time & $(R)$-BAmCl: $57.2 \mathrm{~min} .(S)$-BAmCl: $62.6 \mathrm{~min}$. \\
\hline
\end{tabular}
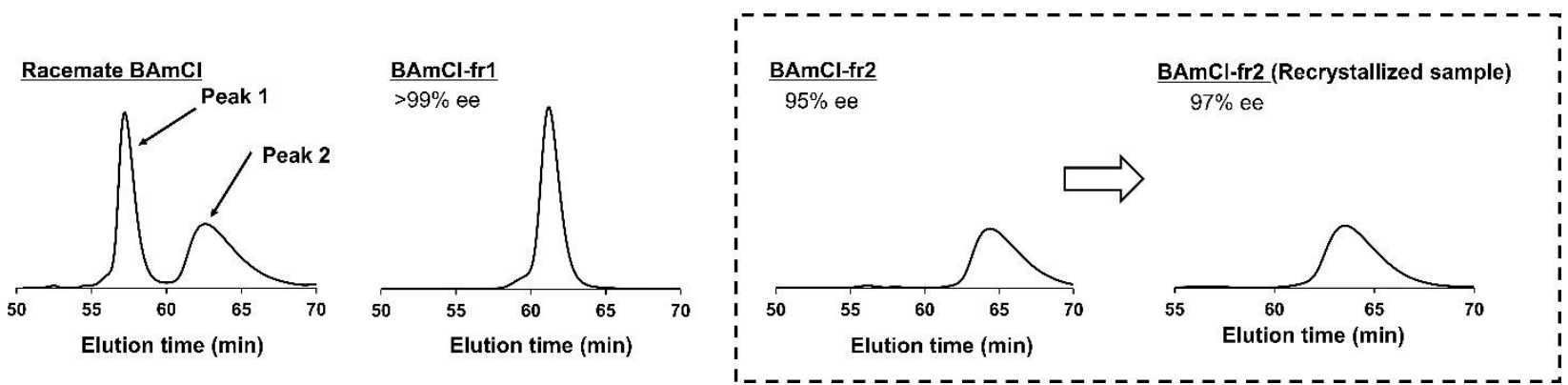

Fig. S9. Chiral HPLC profiles ( $n$-hexane/THF 1/3 (v/v), UV/vis absorption detection at $250 \mathrm{~nm}$ ) of compound BAmCl. 


\section{Circular dichroism (CD) study}
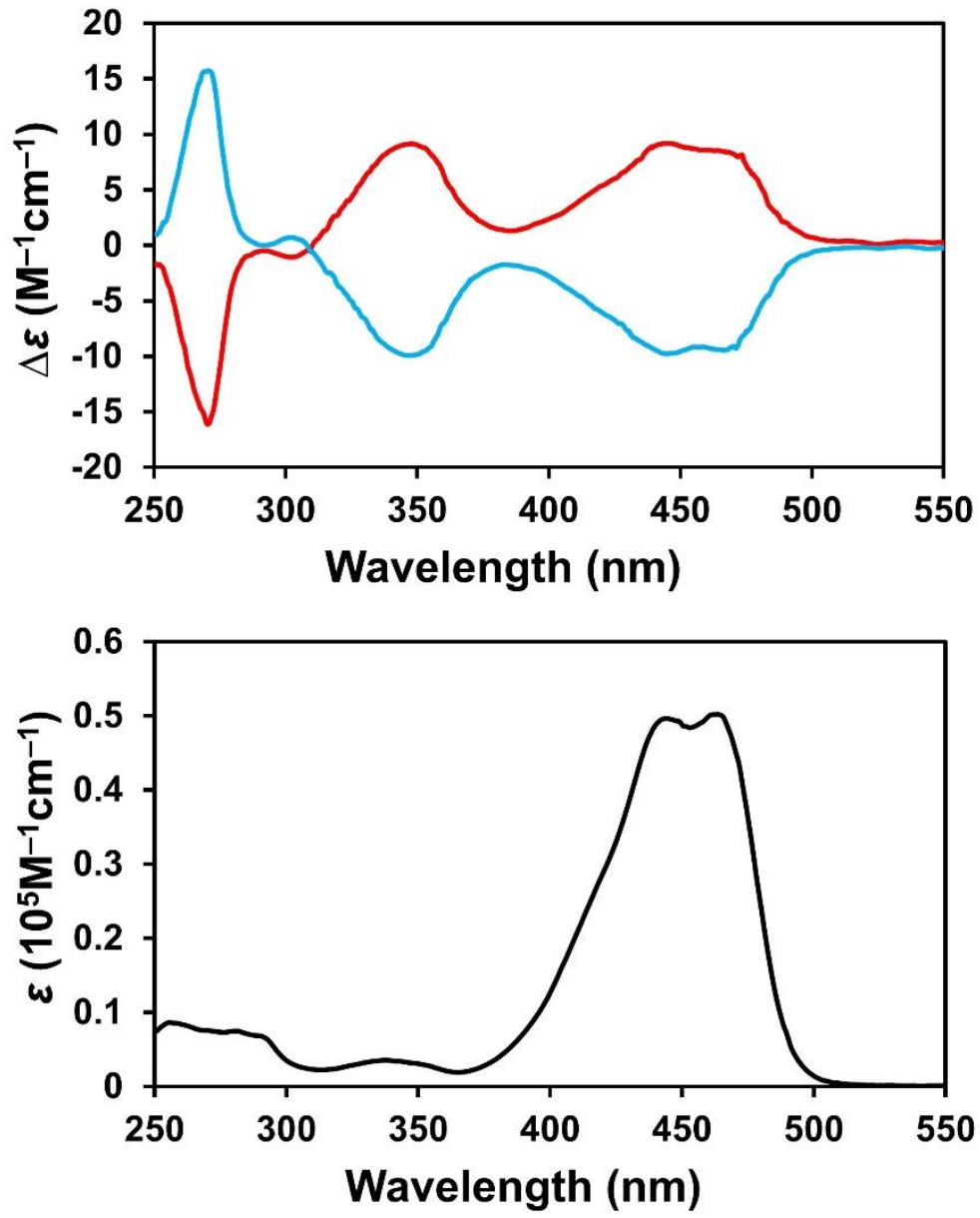

Fig. S10. Circular dichroism (CD) and UV-vis absorption spectra of $2.0 \times 10^{-5} \mathrm{M}$ chloroform solutions containing BAmCl-fr1 (red) and BAmCl-fr2 (blue). 
$\underline{\text { Time-dependent circular dichroism (CD) study }}$

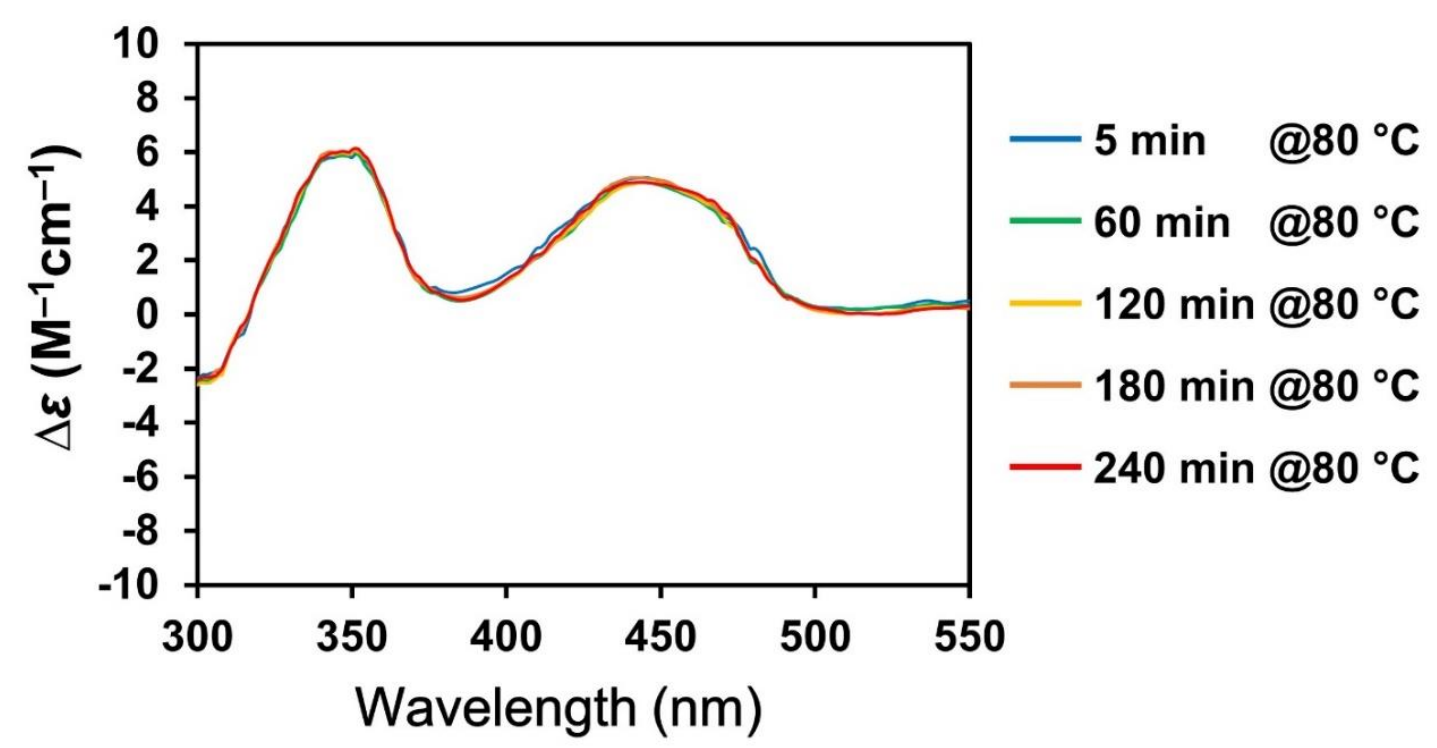

Fig. S11. Time-dependent circular dichroism (CD) spectra of BAmCl-fr1 ((R)-BAmCl) in toluene solution $\left(2.0 \times 10^{-5} \mathrm{M}\right)$ at $80^{\circ} \mathrm{C}$. 


\section{$\underline{\mathrm{X} \text {-ray crystal structure analysis of rac-BAmCl }}$}

Intensity data were collected on a Rigaku R-AXIS RAPID imaging plate area detector with graphite monochromated MoK $\alpha$ radiation $(\lambda=0.71069 \AA)$. The structures were solved and refined by full-matrix least-squares procedures based on $F^{2}$ (SHELXL-2014/7).

Single-crystal of rac-BAmCl was prepared by vapor diffusion method from $\mathrm{CHCl}_{3}$ solution under hexane atmosphere at room temperature.

\begin{tabular}{|c|c|}
\hline \multicolumn{2}{|c|}{ Table S2. Crystallographic data of rac-BAmCl at $78 \mathrm{~K}$} \\
\hline Morphology & Orange block \\
\hline Space group & $P 2_{1} / c$ \\
\hline $\mathrm{a} / \AA$ & $8.4212(8)$ \\
\hline $\mathrm{b} / \AA$ & $14.1413(7)$ \\
\hline $\mathrm{c} / \AA$ & $13.5406(13)$ \\
\hline$\alpha / \operatorname{deg}$ & 90 \\
\hline$\beta / \mathrm{deg}$ & $101.611(7)$ \\
\hline$\gamma / \mathrm{deg}$ & 90 \\
\hline $\mathrm{V} / \AA^{3}$ & $1579.5(3)$ \\
\hline Z & 4 \\
\hline Density $/ \mathrm{g} \mathrm{cm}^{-3}$ & 1.457 \\
\hline Absorption coefficient & 0.265 \\
\hline $\mathrm{F}(000)$ & 720 \\
\hline Crystal size (nm) & $0.30 \times 0.30 \times 0.20$ \\
\hline$\theta$ range for data collection & $3.001-27.485$ \\
\hline Limiting indices & $-10 \leq \mathrm{h} \leq 10,-18 \leq \mathrm{k} \leq 18,-17 \leq \mathrm{l} \leq 17$ \\
\hline Reflections collected (unique) & $14569 / 3118[\mathrm{R}$ (int) $=0.077]$ \\
\hline Completeness to theta $=27.475$ & 0.982 \\
\hline Goodness-off-fit on $F^{2}$ & 1.092 \\
\hline Final $R$ indices $[\mathrm{I}>2 \sigma(\mathrm{I})]^{\mathrm{a}}$ & $R_{1}=0.0507 \mathrm{w} R_{2}=0.1382$ \\
\hline $\mathrm{R}$ indices (all data) & $R_{1}=0.0577 \mathrm{w} R_{2}=0.1432$ \\
\hline$T / \mathrm{K}$ & 78 \\
\hline
\end{tabular}

$[\mathrm{a}] R_{1}=\Sigma\left(\left|F_{0}\right|-\left|F_{\mathrm{c}}\right|\right) / \Sigma\left|F_{0}\right| . \mathrm{w} R_{2}=\left[\Sigma w\left(F^{2}{ }_{0}-F^{2} \mathrm{c}\right) 2 / \Sigma w\left(F^{2}{ }_{0}\right)^{2}\right]^{1 / 2} \cdot \mathrm{w}=1 /\left[\sigma^{2}\left(F^{2}\right.\right.$ $\left.\left.{ }_{0}\right)+\left[(a p)^{2}+b p\right]\right]$, where $\mathrm{p}=\left[\max \left(F_{0}^{2}, 0\right)+2 F^{2} \mathrm{c}\right] / 3$. 
a) $\mathrm{CH} \cdots \mathrm{F}$ interaction

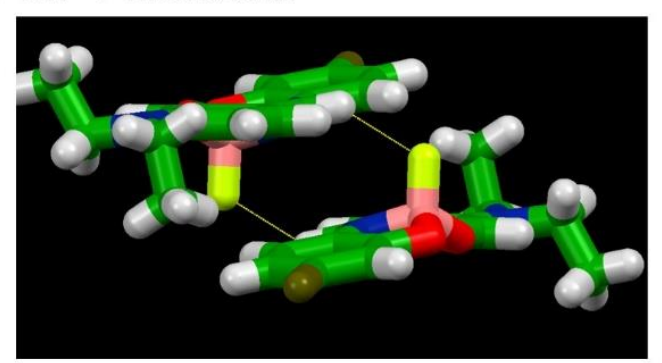

b) $\mathrm{CH} \cdots \pi$ interaction
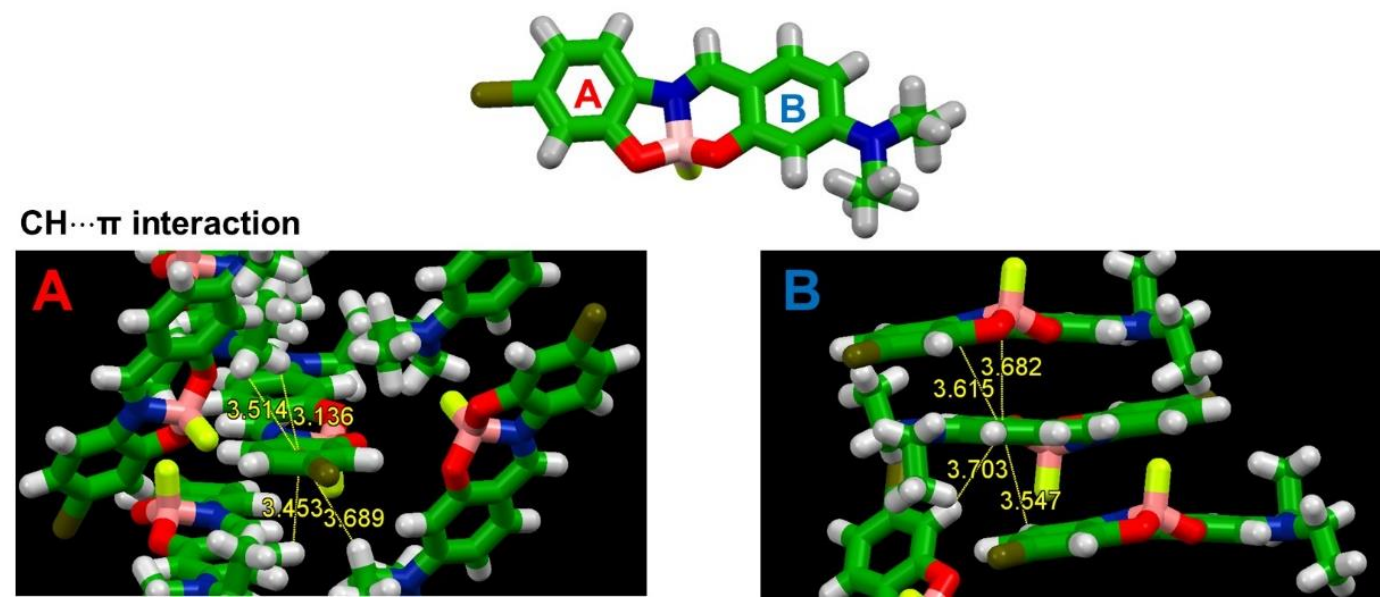

Fig. S12. Intermolecular interaction patterns of $r a c-B A m C l$ a) $\mathrm{CH} \cdots \mathrm{F}$ interaction b) $\mathrm{CH} \cdots \pi$ interaction between hydrogen atoms and aromatic rings $\mathrm{A}$ or $\mathrm{B}$. 


\section{$\underline{\mathrm{X} \text {-ray crystal structure analysis of }(R) \text {-BAmCl }}$}

Intensity data were collected on a Rigaku Saturn 724+ with MicroMax-007HF CCD diffractometer with Varimax Mo optics using graphite-monochromated MoKa radiation. The structures were solved and refined by full-matrix least-squares procedures based on $F^{2}$ (SHELXL-2014/7).

Single-crystal of $(R)$-BAmCl was prepared by vapor diffusion method from THF solution under hexane atmosphere at room temperature.

\begin{tabular}{|c|c|}
\hline \multicolumn{2}{|c|}{ Table S3. Crystallographic data of $(R)$-BAmCl at $143 \mathrm{~K}$} \\
\hline Morphology & Orange needle \\
\hline Space group & $P 3_{2}$ \\
\hline $\mathrm{a} / \AA$ & $12.8397(12)$ \\
\hline $\mathrm{b} / \AA$ & $12.8397(12)$ \\
\hline $\mathrm{c} / \AA$ & $8.5551(11)$ \\
\hline$\alpha / \operatorname{deg}$ & 90 \\
\hline$\beta / \mathrm{deg}$ & 90 \\
\hline$\gamma / \mathrm{deg}$ & 120 \\
\hline $\mathrm{V} / \AA^{3}$ & $1221.4(3)$ \\
\hline $\mathrm{Z}$ & 3 \\
\hline Density $/ \mathrm{g} \mathrm{cm}^{-3}$ & 1.414 \\
\hline Absorption coefficient & 0.257 \\
\hline $\mathrm{F}(000)$ & 540 \\
\hline Crystal size (nm) & $0.360 \times 0.150 \times 0.100$ \\
\hline$\theta$ range for data collection & $3.004-27.462$ \\
\hline Limiting indices & $-15 \leq \mathrm{h} \leq 16,-16 \leq \mathrm{k} \leq 16,-10 \leq \mathrm{l} \leq 11$ \\
\hline Reflections collected (unique) & $219 / 3657[\mathrm{R}(\mathrm{int})=0.0341]$ \\
\hline Completeness to theta $=27.462$ & 0.980 \\
\hline Goodness-off-fit on $F^{2}$ & 1.008 \\
\hline Final $\mathrm{R}$ indices $[\mathrm{I}>2 \sigma(\mathrm{I})]^{\mathrm{a}}$ & $R_{1}=0.0342 \mathrm{w} R_{2}=0.0853$ \\
\hline $\mathrm{R}$ indices (all data) & $R_{1}=0.0386 \mathrm{w} R_{2}=0.0876$ \\
\hline$T / \mathrm{K}$ & 143 \\
\hline
\end{tabular}

[a] $R_{1}=\Sigma\left(\left|F_{0}\right|-\left|F_{\mathrm{c}}\right|\right) / \Sigma\left|F_{0}\right| \cdot \mathrm{w} R_{2}=\left[\Sigma w\left(F^{2}{ }_{0}-F^{2} c\right) 2 / \Sigma w\left(F^{2}{ }_{0}\right)^{2}\right]^{1 / 2} \cdot \mathrm{w}=1 /\left[\sigma^{2}\left(F^{2}\right.\right.$ $\left.\left.{ }_{0}\right)+\left[(a p)^{2}+b p\right]\right]$, where $\mathrm{p}=\left[\max \left(F^{2}, 0\right)+2 F^{2}{ }_{c}\right] / 3$. 
a) $\mathrm{CH} \cdots \mathrm{F}$ interaction

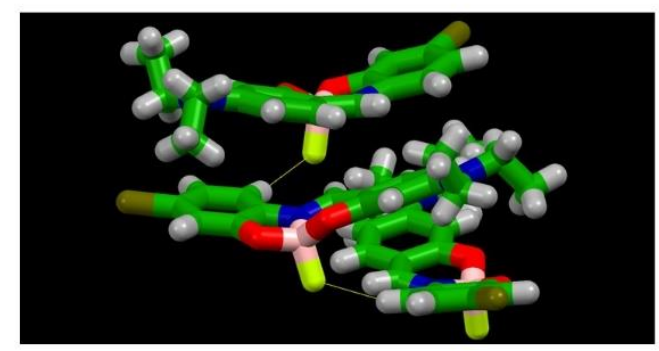

b) $\mathrm{CH} \cdots \mathrm{Cl}$ interaction
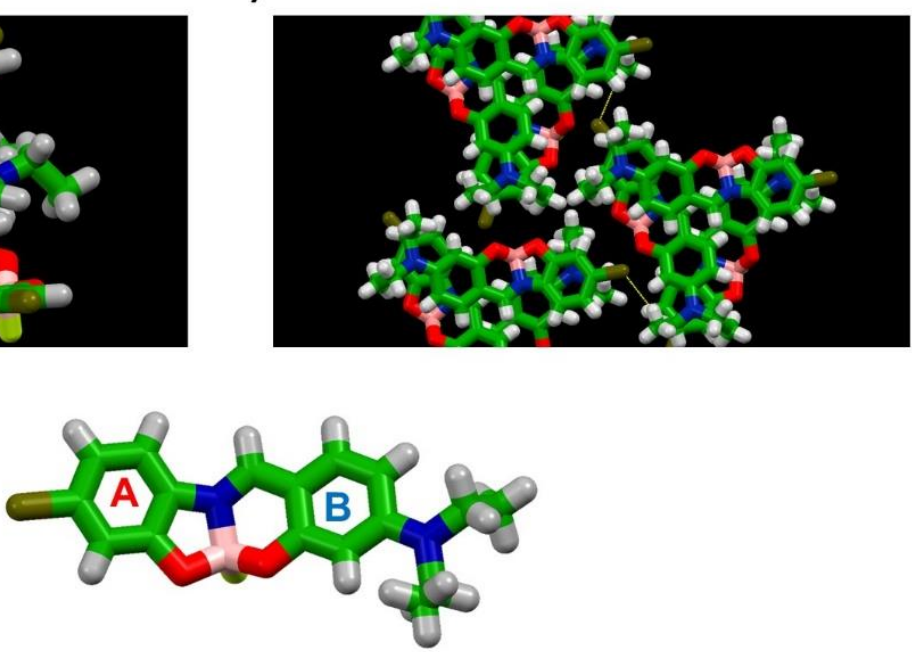

c) $\mathrm{CH} \cdots \pi$ interaction
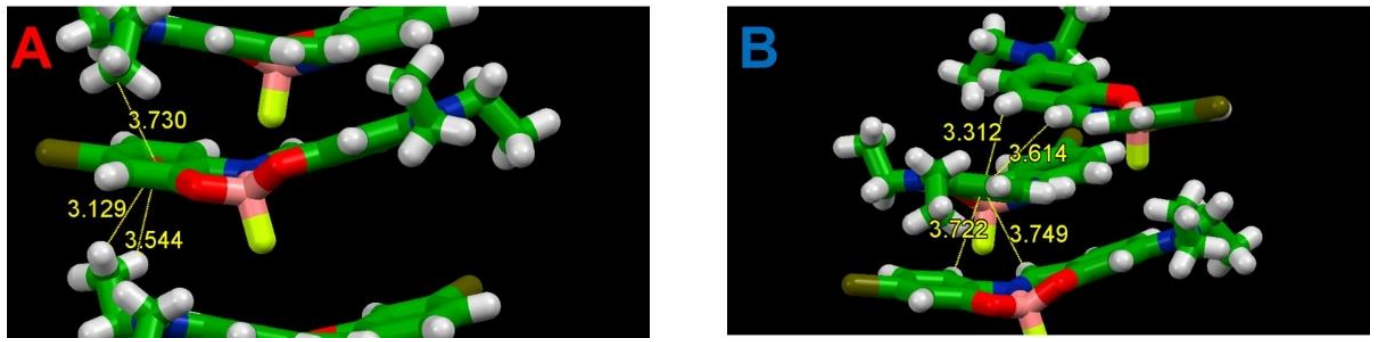

Fig. S13. Intermolecular interaction patterns of $(R)-\mathbf{B A m C l}$. a) $\mathrm{CH} \cdots \mathrm{F}$ interaction $\mathrm{b}$ ) $\mathrm{CH} \cdots \mathrm{Cl}$ interaction c) $\mathrm{CH} \cdots \pi$ interaction between hydrogen atoms and aromatic rings $\mathrm{A}$ or B. 


\section{$\underline{\text { PL lifetime decay curves }}$}
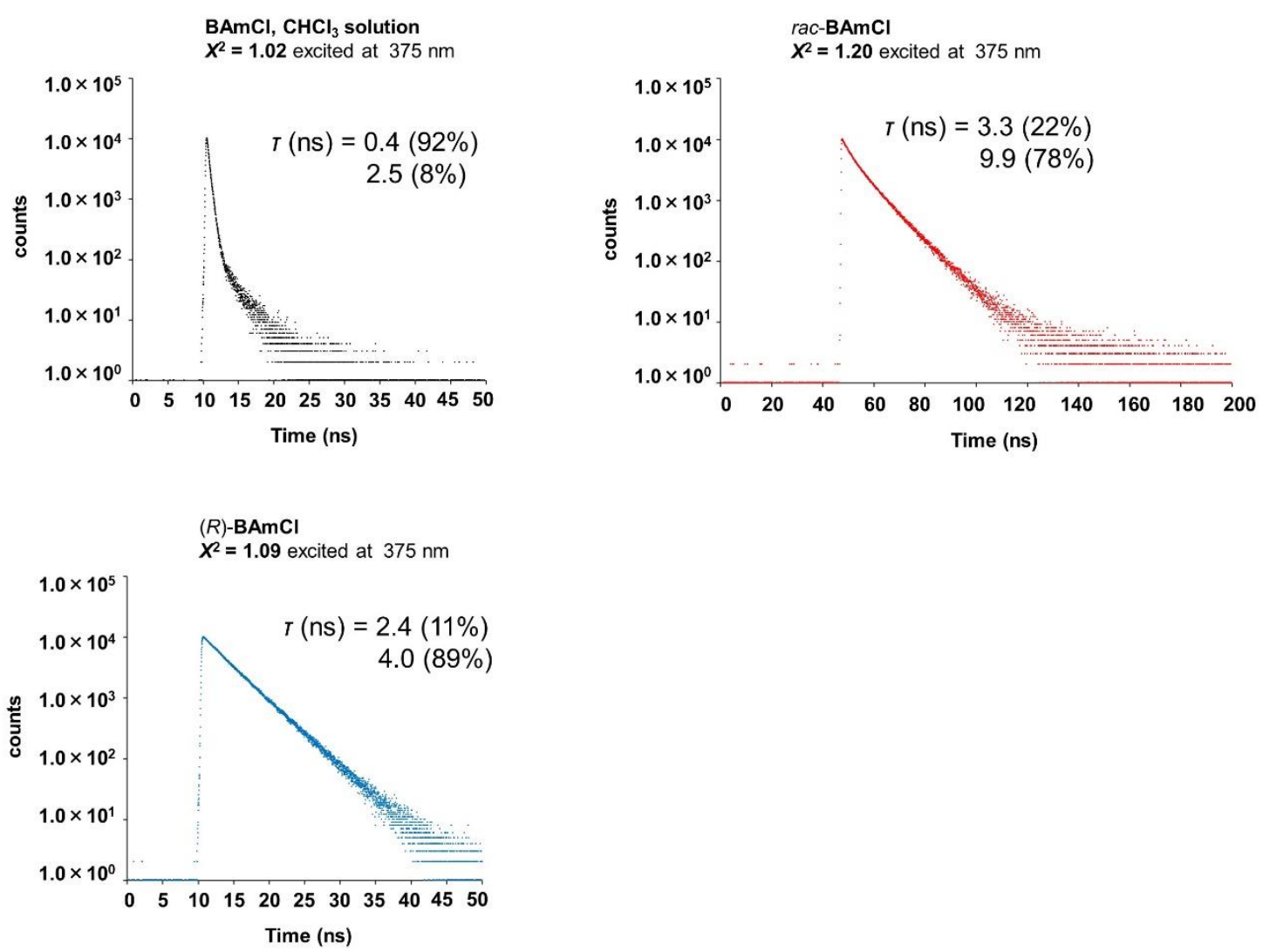

Fig. S14. PL lifetime decay curves of BAmCl in chroloform solution $\left(1.0 \times 10^{-5} \mathrm{M}\right)$ and crystalline states rac-BAmCl and $(R)-\mathbf{B A m C l}$ at room temperature. Their emissions at the PL peak tops were monitored. 


\section{Thermogravimetric analysis (TGA)}

rac- $\mathrm{BAmCl}$ under $\mathrm{N}_{2}$ atmosphere

Heating rate: $10^{\circ} \mathrm{C} / \mathrm{min}$

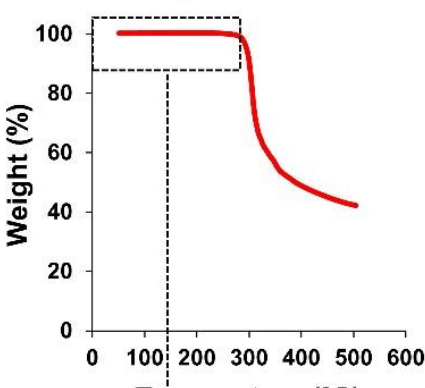

Temperature $\left({ }^{\circ} \mathrm{C}\right)$

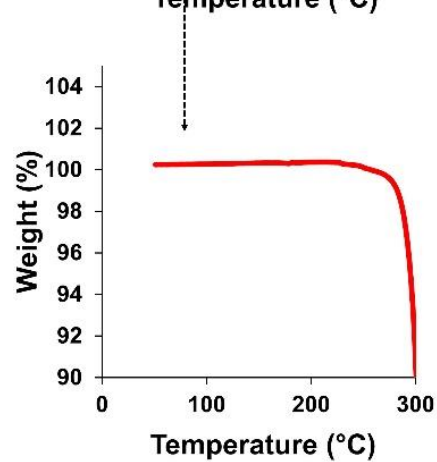

(R)-BAmCl under $\mathrm{N}_{2}$ atmosphere

Heating rate: $10^{\circ} \mathrm{C} / \mathrm{min}$

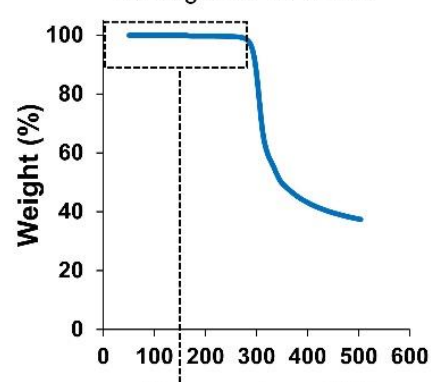

Temperature $\left({ }^{\circ} \mathrm{C}\right)$

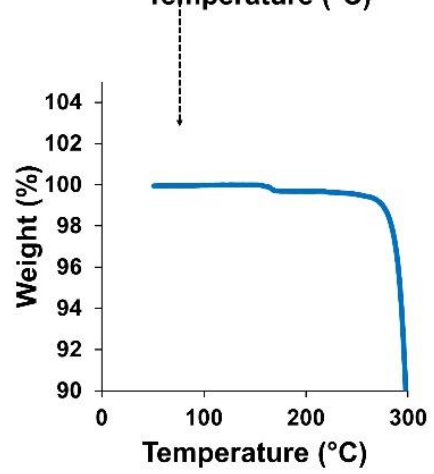

Fig. S15. Thermogravimetric analyses (TGA) curves of rac-BAmCl, $(R)$-BAmCl and (S)-BAmCl.

We investigated about the initial mass loss in TGA curve of $(R)$-BAmCl by using ${ }^{1} \mathrm{H}$ NMR measurement (Figure S15). After heating at $180{ }^{\circ} \mathrm{C}$ for $20 \mathrm{~min},(R)$-BAmCl showed several peaks in aromatic region of ${ }^{1} \mathrm{H}$ NMR. Therefore, we concluded that the initial mass loss was not related to the sublimation or impurity, but to the decomposition of $(R)$-BAmCl.

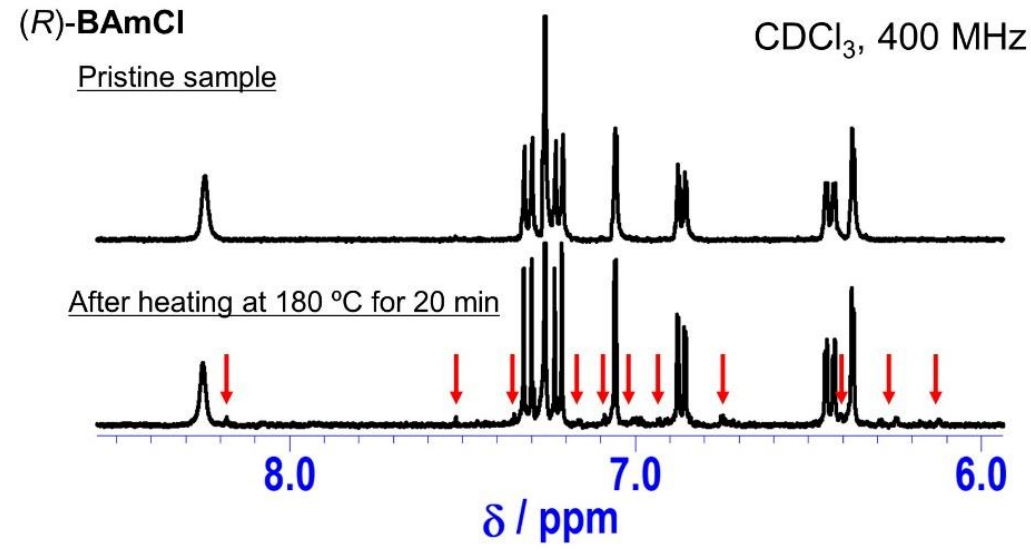

Fig. S16. ${ }^{1} \mathrm{H}$ NMR spectra of pristine and heated $(R)$-BAmCl crystalline sample. 


\section{Differential scanning calorimetric (DSC) analysis}
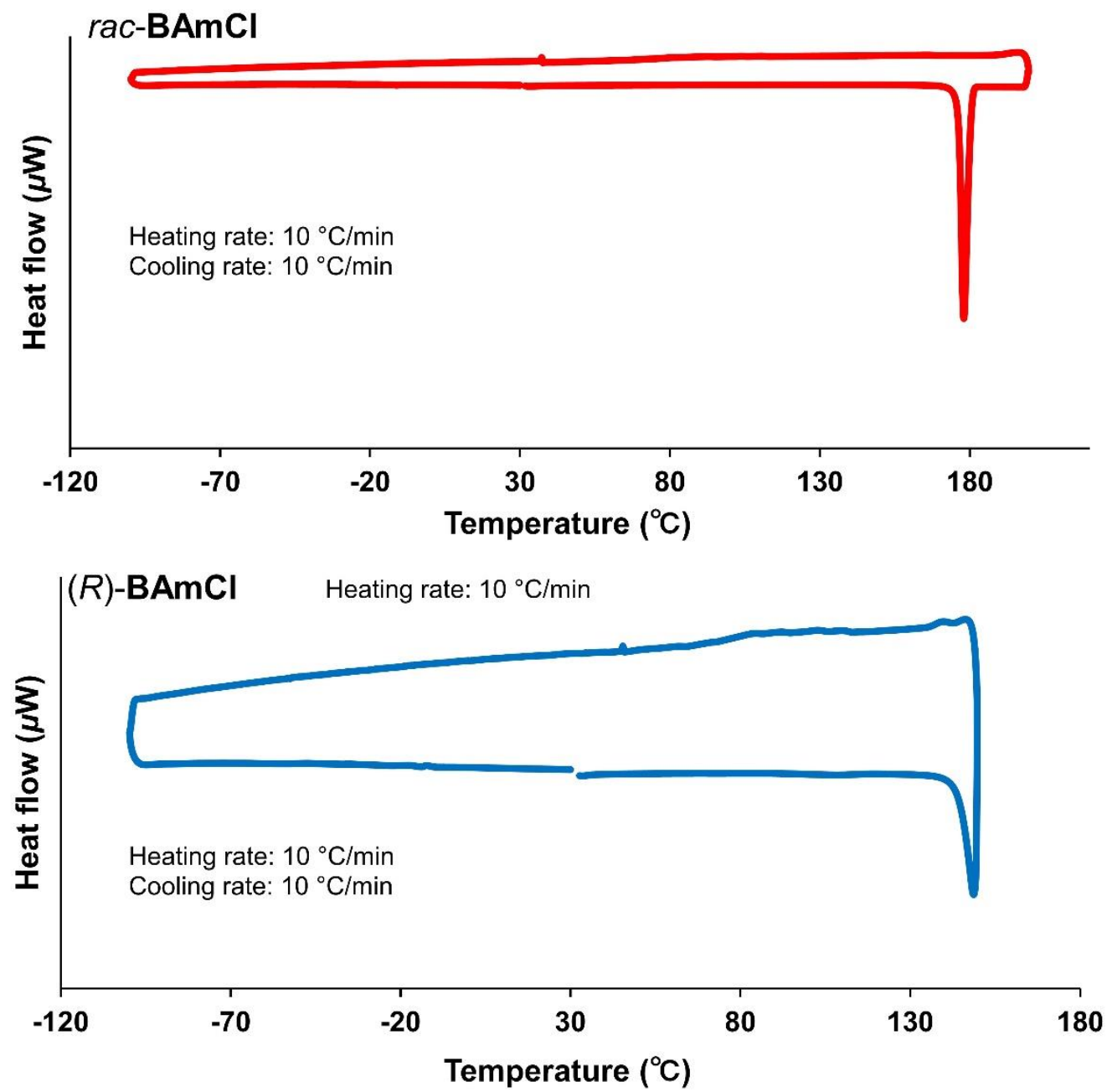

Fig. S17. Differential scanning calorimetric (DSC) curves of rac-BAmCl and $(R)$ BAmCl. 


\section{$\underline{\text { Racemization study of }(R) \text {-BAmCl }}$}

\section{After heating at $120^{\circ} \mathrm{C}$ for $20 \mathrm{~min}$}

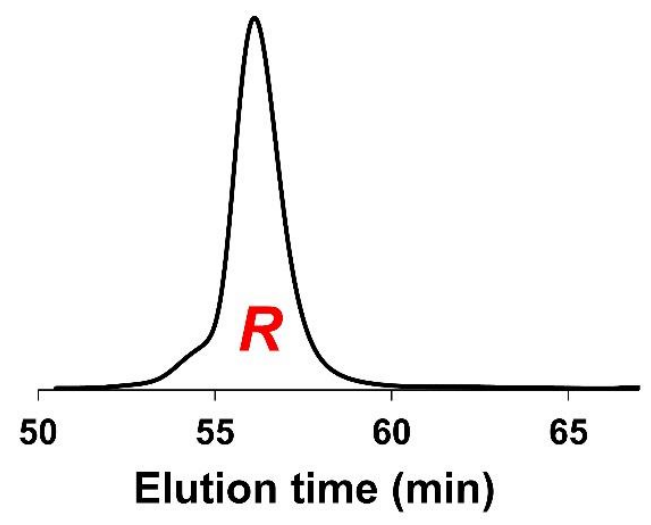

After heating at $150^{\circ} \mathrm{C}$ for $20 \mathrm{~min}$

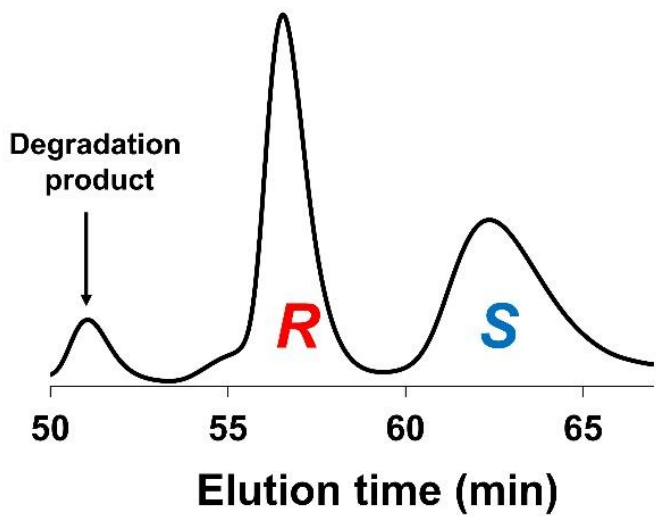

Fig. S18. Chiral HPLC chromatograms ( $n$-hexane/THF 1/3 (v/v), UV/vis absorption detection at $250 \mathrm{~nm})$ of crystalline sample $(R)-\mathbf{B A m C l}$. 

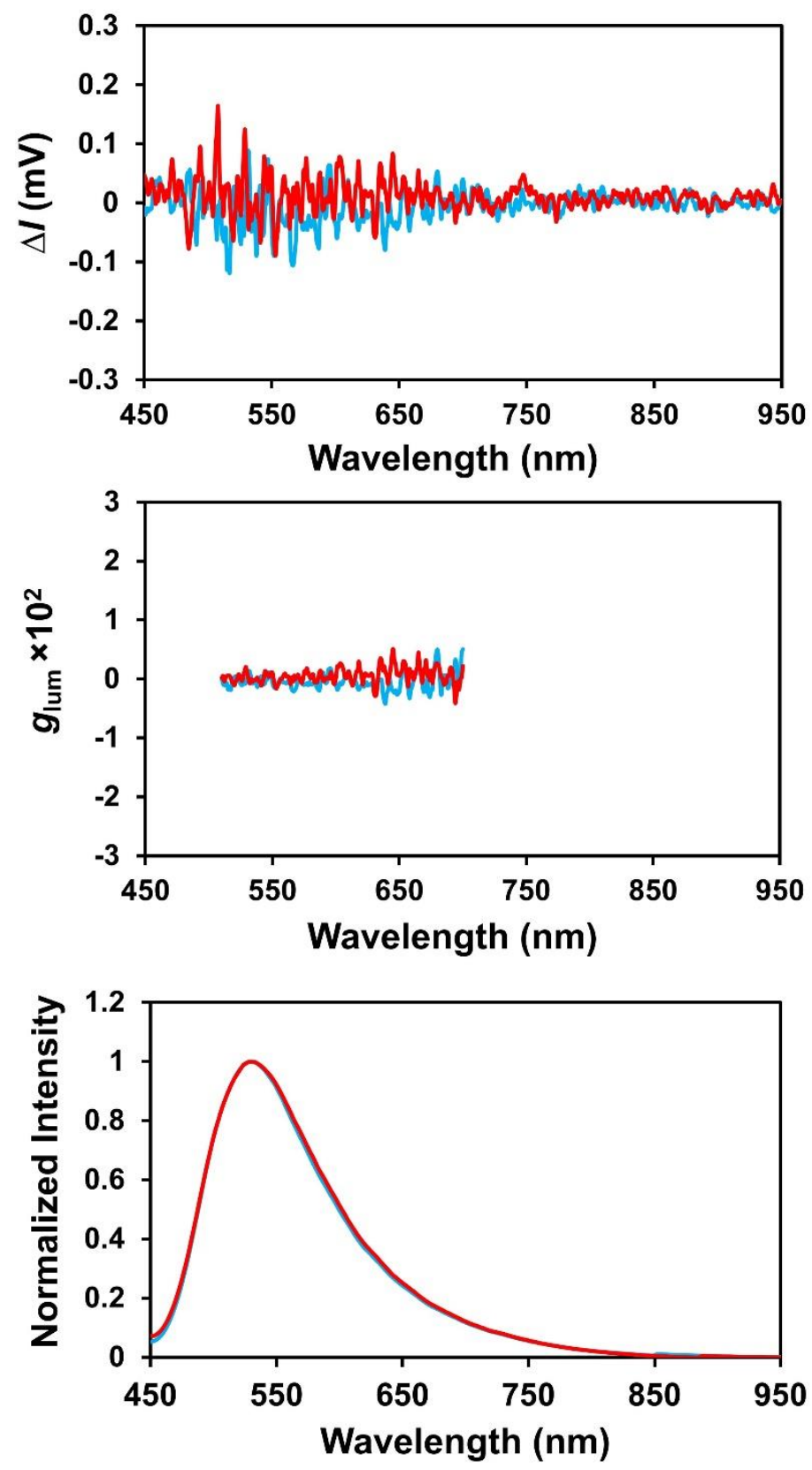

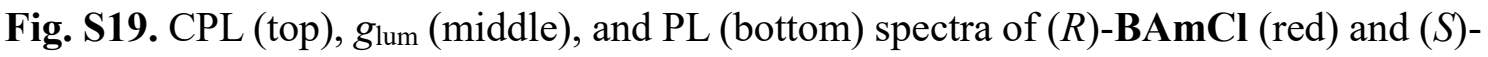
BAmCl (blue) $\mathrm{CHCl}_{3}$ solution $\left(1.0 \times 10^{-4} \mathrm{M}\right)$ excited at $350 \mathrm{~nm}$. 

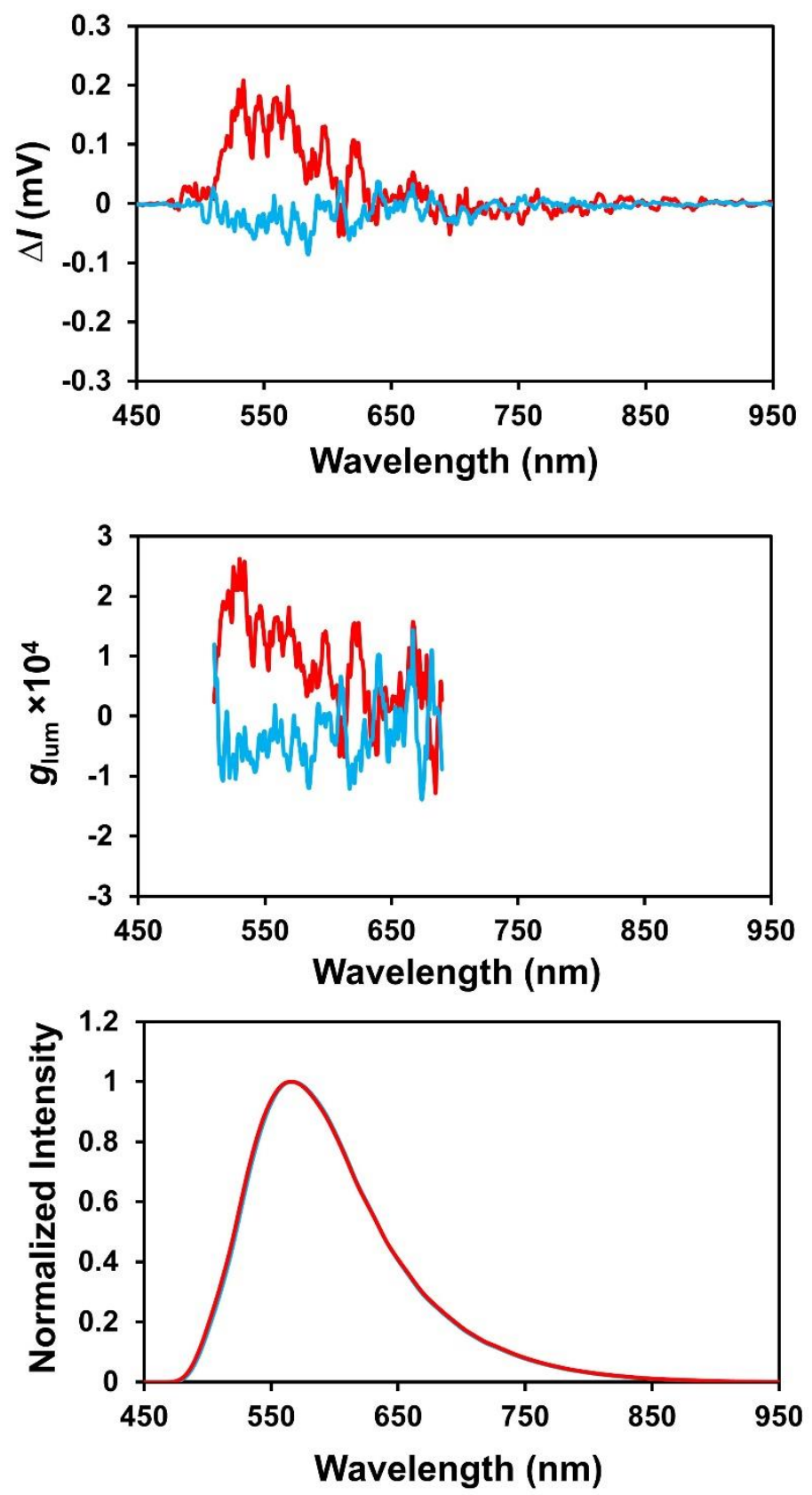

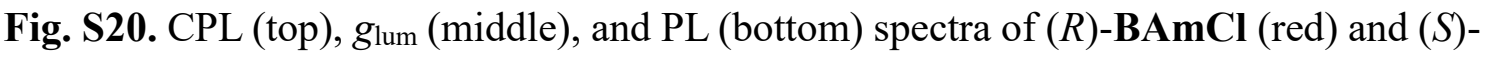
BAmCl (blue) crystalline sample excited at $400 \mathrm{~nm}$. 